\title{
Review
}

\section{Recent Advances in Optical Fiber Enabled Radiation Sensors}

\author{
Jing Zhang ${ }^{1, *}$, Yudiao Xiang ${ }^{1}$, Chen Wang ${ }^{1}$, Yunkang Chen ${ }^{1}$, Swee Chuan Tjin ${ }^{2} \oplus$ and Lei Wei ${ }^{2, *}$ \\ 1 School of Mechanical Engineering and Electronic Information, China University of Geosciences, \\ 388 Lumo Road, Wuhan 430074, China; 1202120782@cug.edu.cn (Y.X.); 1202120758@cug.edu.cn (C.W.); \\ cyk@cug.edu.cn (Y.C.) \\ 2 School of Electrical and Electronic Engineering, Nanyang Technological University, 50 Nanyang Avenue, \\ Singapore 639798, Singapore; esctjin@ntu.edu.sg \\ * Correspondence: zhangjing28@cug.edu.cn (J.Z.); wei.lei@ntu.edu.sg (L.W.)
}

Citation: Zhang, J.; Xiang, Y.; Wang,

C.; Chen, Y.; Tjin, S.C.; Wei, L. Recent

Advances in Optical Fiber Enabled

Radiation Sensors. Sensors 2022, 22,

1126. https://doi.org/10.3390/

s22031126

Academic Editor: Nunzio Cennamo

Received: 30 December 2021

Accepted: 27 January 2022

Published: 1 February 2022

Publisher's Note: MDPI stays neutral with regard to jurisdictional claims in published maps and institutional affiliations.

Copyright: (C) 2022 by the authors. Licensee MDPI, Basel, Switzerland. This article is an open access article distributed under the terms and conditions of the Creative Commons Attribution (CC BY) license (https:// creativecommons.org/licenses/by/ $4.0 /)$.

\begin{abstract}
Optical fibers are being widely utilized as radiation sensors and dosimeters. Benefiting from the rapidly growing optical fiber manufacturing and material engineering, advanced optical fibers have evolved significantly by using functional structures and materials, promoting their detection accuracy and usage scenarios as radiation sensors. This paper summarizes the current development of optical fiber-based radiation sensors. The sensing principles of both extrinsic and intrinsic optical fiber radiation sensors, including radiation-induced attenuation (RIA), radiation-induced luminescence (RIL), and fiber grating wavelength shifting (RI-GWS), were analyzed. The relevant advanced fiber materials and structures, including silica glass, doped silica glasses, polymers, fluorescent and scintillator materials, were also categorized and summarized based on their characteristics. The fabrication methods of intrinsic all-fiber radiation sensors were introduced, as well. Moreover, the applicable scenarios from medical dosimetry to industrial environmental monitoring were discussed. In the end, both challenges and perspectives of fiber-based radiation sensors and fiber-shaped radiation dosimeters were presented.
\end{abstract}

Keywords: optical fiber radiation sensor; multi-material fiber; single crystal optical fiber; radiationinduced attenuation; radiation-induced luminescence; radiation-induced grating wavelength shift

\section{Introduction}

Ionizing radiation science has many applications, ranging from high energy physics, industrial, and medical treatment, to space exploration and national defense. Ionizing radiation consists of electromagnetic waves with sufficiently high energy to ionize atoms and molecules, including the higher energy ultraviolet, the X-rays, and gamma rays (Figure 1) [1,2]. Because of the high energy effects of ionizing radiation on environment and human body, accurate radiation monitoring and dosimetry devices are indispensable. Therefore, semiconductor sensors, photoelectric sensors, and other integrated sensors based on various principles have been widely studied for radiation sensing applications. However, these sensors are easily interfered by electromagnetic fields or other radiation sources, making them malfunction in many scenarios.

Nowadays, optical fiber-based radiation sensors show several unique advantages owing to their material and structural features when being used in radiation sensing [3-8]. Firstly, optical fiber sensors are small in size, light in weight, long in the sensing distance, and flexible to bend. The diameter of commonly used optical fiber is $125 \mu \mathrm{m}$ and the diameters of advanced multi-material multi-functional fibers are a few hundred microns, making the whole fiber-based sensors occupy diameters less than $1 \mathrm{~mm}$. In addition, the fibers are flexible and bendable, making them ideal for attaching to curved surfaces. Therefore, optical fiber sensors can be inserted into narrow, curved, and complex environments, such as the inside of aircraft or the human body, which are suitable for radiation sensing and monitoring. Moreover, fiber-derived sensors provide a much wider monitoring range compared to conventional 
integrated sensors. It is difficult for the conventional integrated sensors to monitor a large area with the point-by-point detection, but for optical fiber sensors being distributed over a very long distance over kilometers, sensing at every point along the fiber becomes possible with the optical time-domain reflectometer (OTDR) technology [6,9]. Secondly, with the prosperous development of the fiber fabrication technology and related material engineering, the optical fiber has been developed from the core-cladding structure based on quartz glass to composite structures with multi-materials, including semiconductors, metals, doped silica glasses, oxide glasses, chalcogenide glasses, and functional polymers [10-18]. The abundance of materials and structures have given optical fiber a new path of development to meet the needs of radiation sensors. More and more sensing materials are being drawn into fiber shapes directly, further increasing the accuracy and length range of sensing. In addition, optical fiber sensors are moisture-proof, corrosion-resistant, and anti-electromagnetic interference at most ambient conditions due to the core-cladding-coating structure. Most optical fibers have the core-cladding structure and, further, can be coated with a protective polymer layer to avoid its functional core contacting with water, making the fiber waterproof. Glasses and coating polymer materials demonstrate superior chemical stability even in highly corrosive environment, enhancing optical fiber sensors' environmental adaptions. Meanwhile, optical fiber sensors are not easily interfered by external electromagnetic fields, because commonly used fiber materials are non-conductive, which can further improve the confidence of sensing.

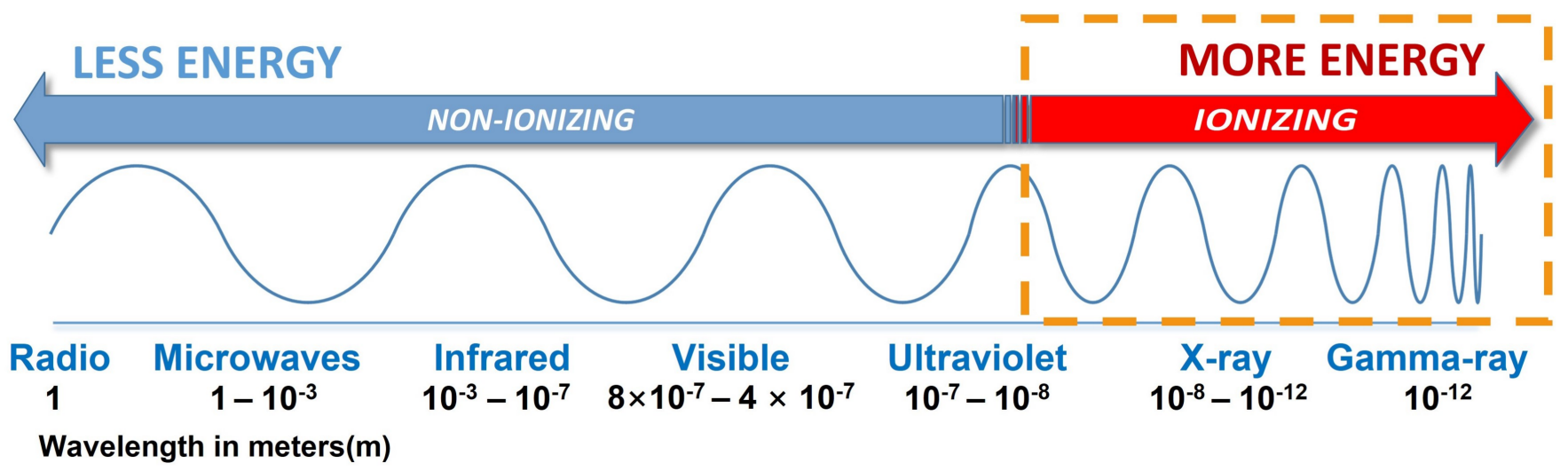

Figure 1. Ionizing and non-ionizing electromagnetic radiation.

In this review, the fundamentals of optical fiber-based radiation sensing are briefly introduced. Then, the fabrication methods of all-fiber radiation sensors are summarized and discussed in detail, including the advanced fiber thermal drawing method, the infiber microstructure generation method, and micron pulling down ( $\mu-P D)$. Afterward, the applications of fiber enabled radiation sensors are presented. In the final section, we give a brief conclusion and outlook.

\section{Fundamentals of Optical Fiber-Based Radiation Sensing}

With the increasing demands of radiation sensing in nuclear energy, aerospace, military, and medical fields, optical fiber-based radiation sensors have attracted researchers' attention. Fiber-based radiation sensors can be divided into two categories according to their working principles, which are intrinsic sensors and extrinsic sensors [4,7]. In the sensing process of an intrinsic fiber radiation sensor, the fiber itself serves as the sensitive element that directly reacts with radiations. The fiber sensor generates signals representing the changes on the fiber, such as structural damage and Bragg wavelength drift, as the result of radiation on materials [19-22]. For the extrinsic fiber radiation sensors, the fiber does not respond to the radiations directly but serves as a transmission channel connecting the sensor unit and signal processing end [23-28]. At present, commonly used intrinsic fiber ra- 
diation sensors include damage, fiber Bragg grating (FBG), fiber long period grating (LPG), and scintillating sensors, while the extrinsic sensors work mostly based on scintillating.

In this section, we will discuss the common sensing principles of extrinsic and intrinsic optical fiber radiation sensors, including radiation-induced attenuation (RIA) (Figure 2a), radiation-induced luminescence (RIL) (Figure $2 b, c)$, and radiation-induced grating wavelength shifting (RI-GWS).

It is worth mentioning that some recent research on artificial intelligence (AI) methods and machine learning methods are used to improve situational awareness, accuracy of data analysis, and control of fiber radiation systems [29,30]. Meanwhile, the neural network type AI can be trained to estimate the radiation in the temporal response, permitting the fiber radiation sensors to be applicable for dosimetry in real time [31].

a

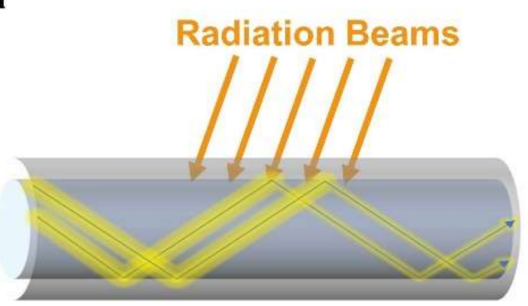

b

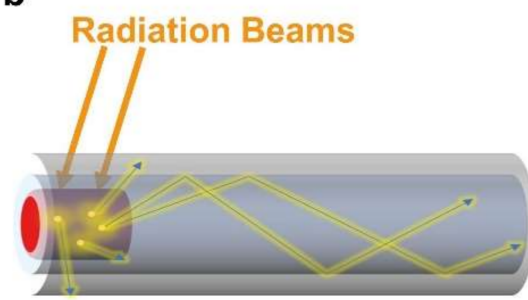

Scintillating Materials
C

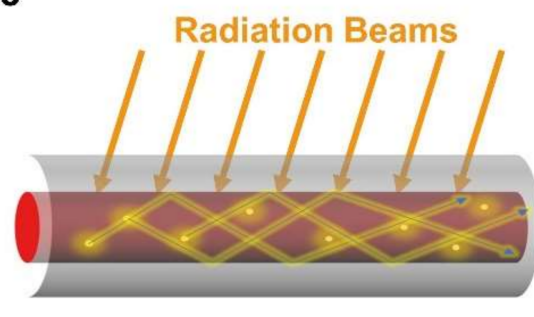

Fiber Core

Fiber Cladding

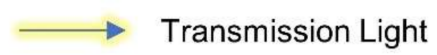

Figure 2. Sensing principles of extrinsic and intrinsic optical fiber radiation sensors. (a) Radiationinduced attenuation based optical fiber radiation sensor. (b) Radiation-induced luminescence based optical fiber radiation sensor with extrinsic scintillator. (c) Radiation-induced luminescence based optical fiber radiation sensor with a scintillating fiber core.

\subsection{Radiation-Induced Attenuation (RIA)}

\subsubsection{Principle of RIA}

Radiation at different wavelengths would generate different effects on the fiber materials. Here we take the silica optical fiber as an example. As shown in Figure 2a, when being radiated by the $\gamma$ rays, the electrons of silica will be ionized to leave with holes. The intrinsic defects, doping defects, impurity defects, and radiation-induced defects can capture these electron-hole pairs to form a specially charged point defect, which is also called the color centers $[32,33]$. These point defects are able to absorb photons, leading to a change in refractive index and a decrease of the transmission light. Likewise, the $\alpha, \beta$, and X-rays interact with silica optical fiber similarly, but their effects vary because of the differences in the energy of rays and the mass of particles. When the radioactive rays pass through the materials, electrons uptake the radiation energy and become free electrons, leaving a hole, and even breaking the original chemical bond when the energy is large enough. The hole can be paired with another electron to form new atomic bonds, resulting in the rearrangement of the atomic structure. If the radioactive rays consist of heavy or high energy particles, the particles could collide with the atomic nucleus and break the atom bonds to form an atomic gap [34,35]. The existence of broken holes, reconstructed atomic structures, and atomic gaps increase the loss of fiber materials while affecting the refractive indexes. Low-power rays cannot provide enough energy to ionize the atoms, introducing defects through electron displacement. For the high-power rays, the electrons are easily ionized, and the atoms also move due to the collision to form defects in the optical fiber. Using the Beer-Lamber law, the radiation-induced absorption growth can be calculated by

$$
\operatorname{RIA}(\mathrm{dB} / \mathrm{km})=-\frac{10}{L} \log \left\{\frac{P_{T}(\lambda, t)}{P_{T}^{0}(\lambda)}\right\}
$$


where $L$ is the irradiated fiber length, $P_{T}(\lambda, t)$ is the measured optical power of the irradiated fiber, $t$ is irradiated time, and $P_{T}^{0}(\lambda)$ is the optical power of the reference fiber [36]. It is worth noting that the point defects or other color centers will not disappear after the radiation is stopped, and that the RIA in optical fibers only decreases with increasing temperature due to the annealing of color centers by heating [37].

The radiation-induced defects and changes of fiber material refractive indexes can be described by the Lorentz-Lorenz formula (Equation (2)) that relates the refractive index of materials to the electronic polarizability of the constituent particles, as well as the Kramers-Kronig relation (Equation (3)), that relates the refractive index to the loss of absorption [38,39]

$$
\begin{gathered}
\Delta n=\frac{\left(n^{2}+2\right)\left(n^{2}-1\right)}{6 n}\left(\frac{\Delta \rho}{\rho}+\frac{\Delta R}{R}\right), \\
\Delta n(\lambda)=\frac{\lambda^{2}}{2 \pi^{2}} \int_{0}^{\infty} \frac{\Delta a(\zeta)}{\lambda^{2}-\zeta^{2}} d \zeta,
\end{gathered}
$$

where $\Delta n$ is the radiation-induced refractive index changes, $\rho$ and $\Delta \rho$ are the density and induced density changes, $R$ and $\Delta R$ is the molar refractivity and its changes, and $\Delta a(\zeta)$ is the photo-bleaching.

Note that, when the total radiation dose becomes large, the degradation of color centers will, eventually, become more significant. It can be observed with the saturation of the RIA value. In addition, RIA value can also be affected by environmental factors, such as temperature. The atoms and molecules move vigorously under a high temperature, which causes the color centers inside the optical fiber to degrade and the RIA value to decrease [40].

\subsubsection{Typical Fiber Radiation Dosimeter Based on RIA}

As shown in Figure 3, many radiation fiber sensors based on the RIA principle have been achieved. As discussed in Section 2.1.1, the silica glass and PMMA can react with radiation rays. These high energy rays impact the atomic structure and atom bonds, leading to the decrease in light transmission. Based on this principle, the commonly used optical fibers based on silica glass are used as radiation sensors (Figure 3a). More recently, some studies have shown that the doped silica has higher sensitivities and radiation resistances, making them promising candidates as radiation sensors, including germaniumdoped silica, nitrogen-doped silica, aluminum-doped silica, and phosphorous-doped silica (Figure 3b, Table 1) [21,41-48]. The modifications and changes in the material components can enable optical fibers to be used in different radiation environments. For example, phosphorous-doped silica fiber was verified to be a good candidate for detecting short time X-ray radiation [41]. As an important branch of optical fibers, polymer optical fibers also demonstrate outstanding performance in radiation sensing applications. The polymer optical fibers (POFs) have distinguished optical transmission wavelengths, good ductility, and outstanding mechanical properties $[49,50]$. The high energy radiation rays can also induce high optical loss into PMMA optical fibers (Figure 3c) [21,47]. Meanwhile, the perfluorinated (PF) POFs are highly radiation sensitive and online radiation monitoring with sensitivity as high as $135 \mathrm{dBm}^{-1} / \mathrm{kGy}$ (Figure 3d) [48,51]. Therefore, some commercial fiber radiation sensors based on polymer materials are developed for low-cost and real-time radiation monitoring [48]. 
a

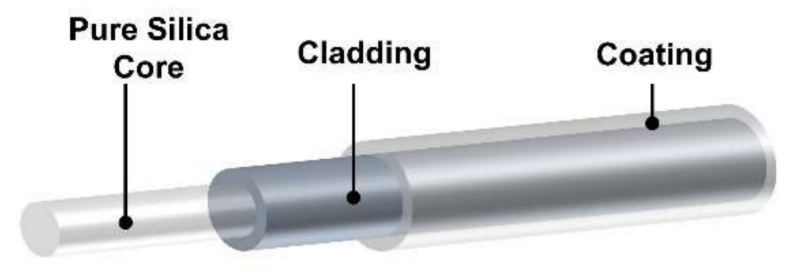

C

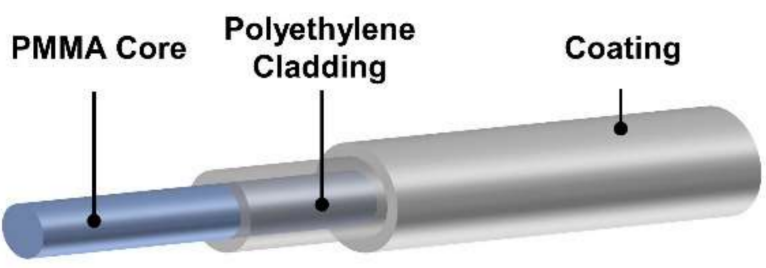

b

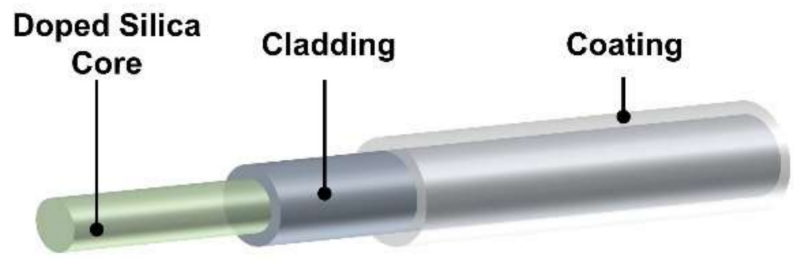

d
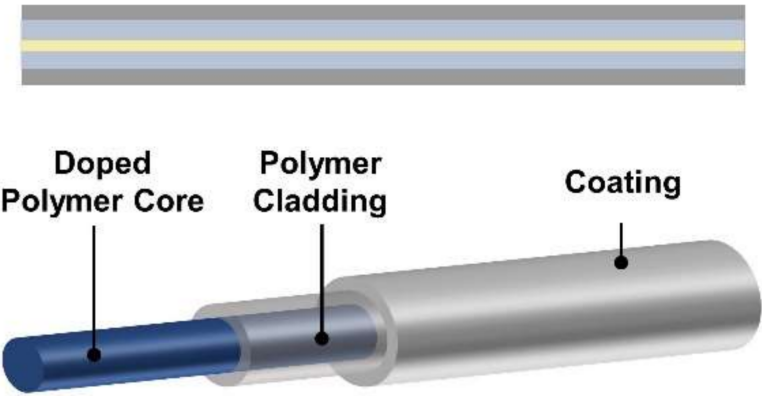
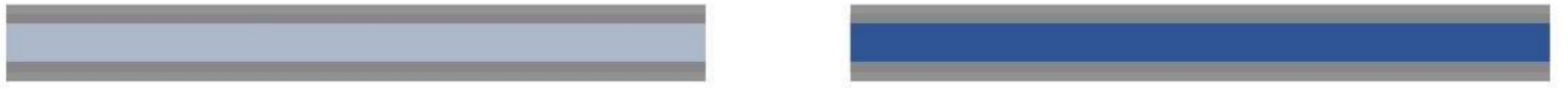

Figure 3. Schematic of widely used fiber radiation sensor based on the RIA principle. $(\mathbf{a}, \mathbf{b})$ silica and doped silica optical fibers. (c,d) PMMA and doped functional polymer optical fibers.

\subsection{Radiation-induced Luminescence (RIL)}

\subsubsection{Principle of RIL}

As shown in Figure $2 b, c$, another conventional method for detecting the radiation dose is to measure the materials scintillation intensity under radiations, including radioluminescence (RL), thermoluminescence (TL), and optically-stimulated luminescence (OSL).

Radioluminescence (RL) is an effect in which atoms are excited into a high-energy state by absorption of radiation energy and then generate photons through spontaneous emission. Some wavelengths of radioluminescence are located at the visible and infrared bands, which can transmit through optical fiber and be collected by the analysis instruments $[25,27,52,53]$. The radiation power is then calculated by counting the number of photons or measuring the light intensity. The effects of radiation-induced thermoluminescence (TL) and optically stimulated luminescence (OSL) have similar principles [54-56]. These effects relate to the impurities that create localized energy levels within the forbidden energy gap. When the TL and OSL materials are ionized by radiation rays, free electrons and holes are excited and then trapped by the lattice defects or impurity in the material during the transition. Heat or light energy can help the excited electrons and holes escape from the traps to combine and stimulate photons. The number of captured electrons before saturation is highly dependent on the radiation dose. The intensities of TL and OSL are also proportional to temperature.

\subsubsection{Typical Fiber Radiation Dosimeter Based on RIL}

As discussed in the previous section, the RIL includes several detection principles, such as RL, TL, and OSL, based on extrinsic sensing and intrinsic sensing structures. For the extrinsic fiber sensor, a scintillator will be used to react with radiation rays and to emit photons. As shown in Figure $4 a-c$, the scintillating materials are fixed to the optical fiber end face by bonding, inlaying, or wrapping to detect the radiation rays. Then the generated photons from the scintillating materials are collected by the connected optical fiber and transmitted to the photodetectors. The optical fiber only performs the function of optical signal transmission. The detection of radiation rays is realized by the extrinsic scintillating materials, such as rare earth element doped inorganic scintillators (NaI, CsI, 
$\mathrm{KBr}, \mathrm{Gd}_{2} \mathrm{O}_{3}, \mathrm{Al}_{2} \mathrm{O}_{3}, \mathrm{YVO}_{4}$ ) and plastic scintillators (Quantum Dots Doped PMMA and Polystyrene), etc. [23-25,28,53,57-61]. These extrinsic fiber radiation sensors still have some inherent limitations. On one hand, the optical signal stimulated by radiation rays suffers from optical scattering and other energy loss due to the connecting interface, reducing the accuracy and measurement limits of sensing. On the other hand, the range of measurement is also limited by the length of the scintillating materials, decreasing radiation capture and detection efficiency. Meanwhile, the robustness of this feature needs to be improved.

a

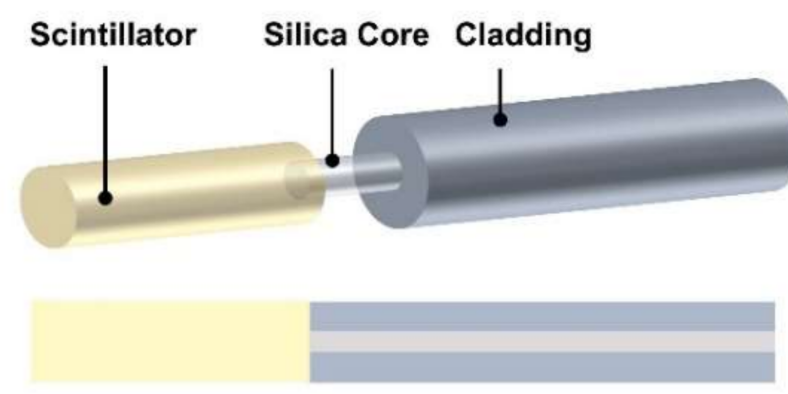

C

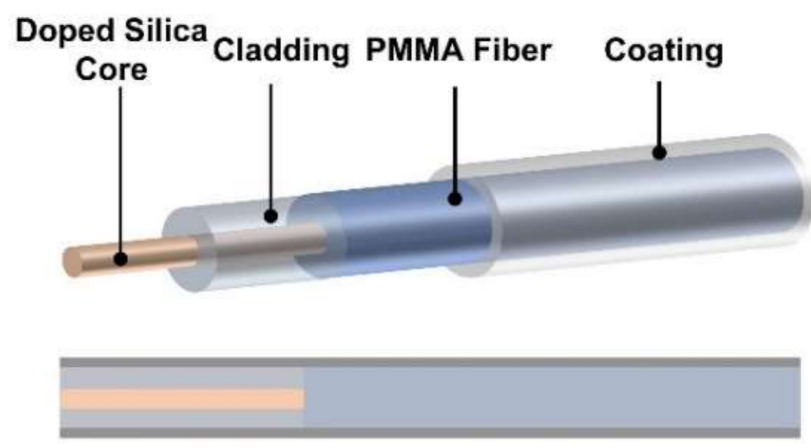

b

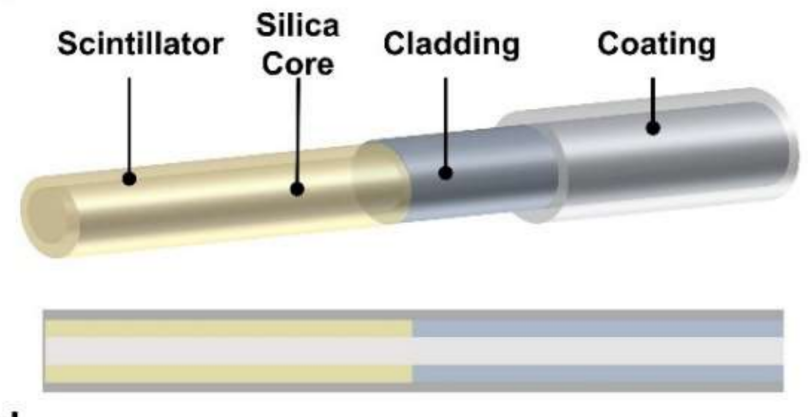

d

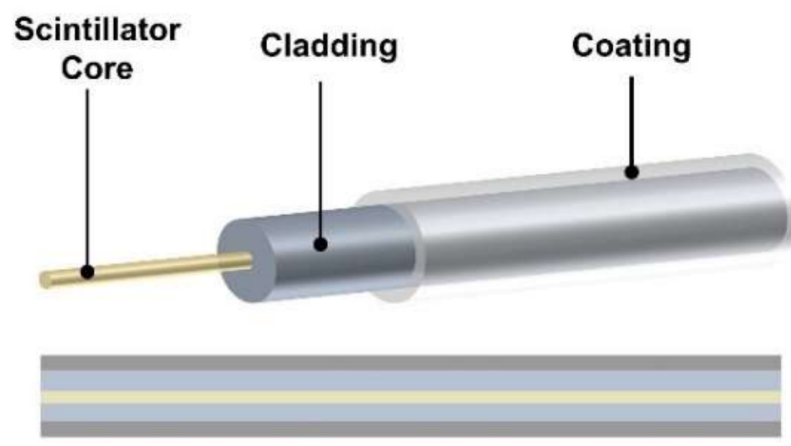

Figure 4. Schematic of widely used fiber radiation sensor based on the RIL principle. (a) Scintillatorconnected optical fibers radiation sensor. (b) Scintillator-covered-optical fibers radiation sensor. (c) Limited length RIL radiation fiber sensor. (d) All-fiber RIL radiation fiber sensor.

To improve the radiation-capturing capability, detection length/accuracy, and robustness of devices, all-fiber RIL radiation fiber sensors were developed as intrinsic sensing (Figure $4 \mathrm{~d}$ ). Based on the development of the fiber thermal drawing process and material engineering, scintillating materials, such as rare earth element doped silica, Ce doped $\mathrm{YAlO}_{3}, \mathrm{Ce}$ doped $\mathrm{Lu}_{1.8} \mathrm{Y}_{2} \mathrm{SiO}_{3}$, etc., are inserted into the fiber cladding tube and drawn into scintillating fibers directly (Table 1) [62-72]. For the intrinsic RIL fiber sensor, the fiber not only transmits the generated photons, but also serves as the light emitting element that directly reacts with radiations.

\subsection{Radiation-induced Grating Wavelength Shifting (RI-GWS)}

As mentioned above, the radiation energy will induce the defect points and crystal structure changes, leading to changes of the refractive index of fiber materials. In addition, the radiation-induced effects also induce the temperature changes based on the thermooptic parameters, leading to the changes in material density and grating periods [73]. These changes will not only induce the RIA phenomenon but can also lead to a wavelength shifting phenomenon based on fiber Bragg grating (FBG) and long period optical fiber 
grating (LPG), accordingly (Figure 5) [74-76]. The radiation-induced Bragg wavelength shifting (BWS) $\Delta \lambda_{B}$ can be calculated by

$$
\frac{\Delta \lambda_{B}}{\lambda_{B}}=\frac{\Delta n_{\text {rad }}}{n_{\text {eff }}}+\frac{\Delta \Lambda}{\Lambda}
$$

where $\lambda_{B}$ is $\sim 1550 \mathrm{~nm}$ for FBG, $\Delta n_{\text {rad }}$ is radiation-induced effective refractive index, $n_{\text {eff }}$ is the effective refractive index, $\Lambda$ and $\Delta \Lambda$ are the grating period and grating period changes. As the wavelength shifts of FBG are sensitive to the change of radiation but not to the intensity of radiation, the FBG radiation sensors are suitable for strong radiation scenarios at high temperatures. In 2006, Krebber et al. demonstrated the capability of using FBG fibers for radiation sensing under an intense radiation (>2 kGy) [75]. In 2018, Mas et al. used an FBG fiber to monitor the radiation dose inside the MIT nuclear reactor (MITR) under a temperature higher than $600{ }^{\circ} \mathrm{C}$ and the radiation power higher than 1 $\mathrm{MeV}$, which clearly illustrates the potential of using FBG sensors in nuclear power plants monitoring. The Bragg wavelength recorded during the experiment presents a stable shift to the short wavelength at the rate of $0.1 \mathrm{~nm} /$ day [77]. Recently, LPG optical fiber sensors have shown a large potential in the field of radiation sensing. In 2015, Sporea et al. proved the sensitivity of $1.2 \mathrm{~nm} / \mathrm{kGy}$ to gamma exposure based on LPG, manufactured by the melting-drawing method based on $\mathrm{CO}_{2}$ laser and assisted by a micro-flame [78]. In 2017, Stancălie et al. reported the real-time monitoring of mixed neutron and gamma flux based on the spectral of LPG, written by the electric arc discharge (EDA) technique [73]. In 2018, a temperature-compensated radiation sensor based on two LPG fiber sensors was developed by Stancălie et al. [79]. In 2020, Berruti et al. achieved an uncoated LPG radiation sensor based on a commercial B-Ge codoped optical fiber for multi-parametric sensing in high radiation environments [80]. The sensitivity of the LPG device to an external factor can be expressed as

$$
\frac{\delta \lambda_{\text {res }}{ }^{(n)}}{\delta \chi}=\gamma^{(n)} \times \lambda_{\text {res }}{ }^{(n)} \times\left[\frac{1}{\Delta n_{e f f}{ }^{(n)}} \times \frac{\delta \Delta n_{e f f}{ }^{(n)}}{\delta X}+\alpha_{X}\right],
$$

where $\chi$ is the external parameter, $\lambda_{\text {res }}{ }^{(n)}$ is the resonant wavelength of LPG, $\gamma^{(n)}$ is the dispersion parameter of mode $n, \alpha_{\chi}$ is the external factor-induced change of the grating period. From the results of the current study, it appears that the fiber radiation sensors based on LPG have a higher sensitivity of radiation dose than the sensors based on FBG $[78,79,81]$.

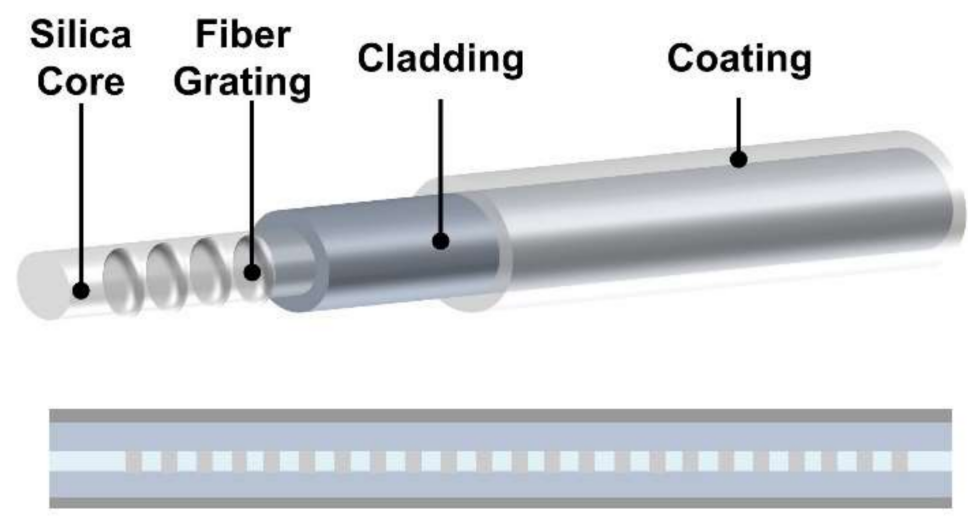

Figure 5. Schematic of fiber grating for radiation-induced wavelength shifting sensing. 
Table 1. Fiber-based Radiation Sensors.

\begin{tabular}{|c|c|c|c|c|}
\hline Principle & Structure & Material & Ionizing Radiation & Refs. \\
\hline \multirow{5}{*}{$\begin{array}{l}\text { Radiation-induced } \\
\text { Attenuation (RIA) }\end{array}$} & \multirow{5}{*}{ Intrinsic Fiber Sensor } & $\begin{array}{l}\text { P Doped and P/Ce } \\
\text { Codoped Silica }\end{array}$ & $\begin{array}{l}\text { X-ray, Gamma-ray, and Beta } \\
\text { Particle }\end{array}$ & [42-45] \\
\hline & & Al Doped Silica & $\begin{array}{c}\text { X-ray (0-500 Gy), and Beta } \\
\text { Particle }\end{array}$ & {$[44,46]$} \\
\hline & & N Doped Silica & X-ray & {$[41]$} \\
\hline & & PMMA & Gamma-ray & {$[21,47]$} \\
\hline & & Perfluorinated Polymer & Gamma-ray (0-100 Gy) & [48] \\
\hline \multirow{3}{*}{$\begin{array}{l}\text { Optically Stimulated } \\
\text { Luminescence (OSL) }\end{array}$} & $\begin{array}{l}\text { Extrinsic Sensor } \\
\text { Connected to Fiber }\end{array}$ & Eu Doped KBr & Gamma-ray & [57] \\
\hline & \multirow{2}{*}{ Intrinsic Fiber Sensor } & Ge Doped Silica & Beta Particle & [82] \\
\hline & & Fluoride Phosphate Glass & Beta Particle & {$[83,84]$} \\
\hline \multirow{4}{*}{$\begin{array}{l}\text { Thermo- } \\
\text { Luminescence } \\
\text { (TL) }\end{array}$} & \multirow{4}{*}{ Intrinsic Fiber Sensor } & Nd Doped Silica & X-ray & [62] \\
\hline & & Ge Doped Silica & $\begin{array}{c}\text { Gamma-ray, Alpha Particle, } \\
\text { and Proton Beam }\end{array}$ & [63-66] \\
\hline & & Al Doped Silica & Alpha Particle & {$[65]$} \\
\hline & & Al-Tm Codoped Silica & Gamma-ray & [67] \\
\hline \multirow{18}{*}{$\begin{array}{l}\text { Radio-Luminescence } \\
\text { (RL) }\end{array}$} & \multirow{9}{*}{$\begin{array}{l}\text { Extrinsic Sensor } \\
\text { Connected to Fiber }\end{array}$} & $\mathrm{Tb}$ Doped $\mathrm{Gd}_{2} \mathrm{O}_{2} \mathrm{~S}$ & X-ray and Beta Particles & {$[28,53,58-60]$} \\
\hline & & $\mathrm{Tb} / \mathrm{Ce}$ Codoped $\mathrm{Gd}_{2} \mathrm{O}_{3}$ & X-ray & {$[61]$} \\
\hline & & Cr Doped $\mathrm{Al}_{2} \mathrm{O}_{3}$ & $\begin{array}{c}\text { Gamma-ray and Beta } \\
\text { Particle }\end{array}$ & [23-25] \\
\hline & & Eu Doped $\mathrm{YVO}_{4}$ & Gamma-ray & [24] \\
\hline & & Ti Doped CsI & $\begin{array}{c}\text { Gamma-ray and Beta } \\
\text { Particle }\end{array}$ & {$[24,28]$} \\
\hline & & $\begin{array}{l}\text { Eu Doped and } \mathrm{Eu} / \mathrm{Li} \\
\text { Codoped } \mathrm{Y}_{2} \mathrm{O}_{3}\end{array}$ & Gamma-ray & {$[24,26,27]$} \\
\hline & & $\mathrm{ZnWO}_{4}$ & Beta Particle & [28] \\
\hline & & $\begin{array}{l}\text { Quantum Dots Doped } \\
\text { PMMA }\end{array}$ & X-ray (20-500 cGy) & [85] \\
\hline & & Polystyrene & Gamma-ray & [86] \\
\hline & \multirow{4}{*}{ Intrinsic Fiber Sensor } & Ce Doped Silica & X-ray and Proton Beam & {$[68,69,87]$} \\
\hline & & Pr Doped Silica & X-ray and Gamma-ray & [70] \\
\hline & & Tb Doped Silica & X-ray & [88] \\
\hline & & Gd Doped Silica & Proton Beam & [89] \\
\hline & \multirow{5}{*}{$\begin{array}{l}\text { Extrinsic Sensor } \\
\text { Connected to Fiber and } \\
\text { Intrinsic Fiber Sensor }\end{array}$} & $\mathrm{Bi}_{2} \mathrm{O}_{3}-\mathrm{GeO}_{2}(\mathrm{BGO})$ & X-ray & [90] \\
\hline & & Ce Doped $\mathrm{YAlO}_{3}(\mathrm{YAP})$ & Gamma-ray & [91] \\
\hline & & Ce Doped $\mathrm{Y}_{3} \mathrm{Al}_{5} \mathrm{O}_{12}$ & Beta Particle & {$[28]$} \\
\hline & & $\mathrm{Lu}_{3} \mathrm{Al}_{5} \mathrm{G}_{23}$ & $\begin{array}{l}\text { Gamma-ray and Proton } \\
\text { Beam }(0-100 \mathrm{kGy})\end{array}$ & {$[71,72]$} \\
\hline & & $\begin{array}{c}\text { Ce Doped } \mathrm{Lu}_{1.8} \mathrm{Y}_{2} \mathrm{SiO}_{5} \\
\text { (LYSO) }\end{array}$ & Gamma-ray & [92] \\
\hline \multirow{2}{*}{$\begin{array}{l}\text { Radiation-induced } \\
\text { Grating Wavelength } \\
\text { Shift (RI-GWS) }\end{array}$} & Fiber Bragg Grating & Ge/B Codoped Silica & Gamma-ray (0-116 kGy) & {$[93]$} \\
\hline & Long Period Grating & $\begin{array}{l}\text { Ge/B doped or Pure Silica } \\
\text { Core and F Doped Cladding }\end{array}$ & Gramma-ray & [78-81,94-97] \\
\hline
\end{tabular}




\section{Fabrication Method of the Intrinsic Fiber Radiation Sensor}

As discussed in Section 2, the optical fiber radiation sensors can be broadly classified into extrinsic and intrinsic sensors. For the extrinsic fiber radiation sensors, the radiation luminescence and radiation damages only occur in the extrinsic sensing part. The shape, length, and connection process of the extrinsic sensing materials limit their application, making them unsuitable for large-scale sensing. For the intrinsic fiber radiation sensors, the radiation luminescence and radiation damages occur in the fiber materials directly, greatly improving the sensitivity and sensing coverage. In this section, we will introduce the advances of the fabrication methods of the intrinsic fiber radiation sensors.

\subsection{Micro Pulling-Down ( $\mu-P D)$ Method and Laser Heated Pedestal Growth (LHPG) Method}

The single crystals of $\mathrm{Bi}_{2} \mathrm{Ge}_{3} \mathrm{O}_{12}$ (BGO, melting temperature of $\left.1050{ }^{\circ} \mathrm{C}\right), \mathrm{Lu}_{3} \mathrm{Al}_{5} \mathrm{G}_{12}$ ( $\mathrm{LuAG}$, melting temperature of $1980^{\circ} \mathrm{C}$ ), $\mathrm{Y}_{3} \mathrm{Al}_{5} \mathrm{O}_{12}$ (YAG, melting temperature of $\sim 1940{ }^{\circ} \mathrm{C}$ ), $\mathrm{YAlO}_{3}$ (YAP, melting temperature of $\sim 1934{ }^{\circ} \mathrm{C}$ ) are promising scintillating materials [4]. As shown in Figure 6, the micro pulling-down ( $\mu$-PD) method and laser heated pedestal growth (LHPG) method are widely used as crystal growth techniques $[91,98,99]$. For both methods, a crystal seed is used to guarantee the orientation and crystal structure of the grown crystal. A heating chamber for the $\mu$-PD method or laser heating source for the LHPG method is involved to melt the target materials. Then the crystal seed is pulled slowly and continuously. The new single crystal grows on the liquid/solid interface. Furthermore, to enhance the RIA and RIL effects, rare earth elements, such as $\mathrm{Bi}, \mathrm{Eu}$, and $\mathrm{Ce}$, are also doped into these single crystals.

a

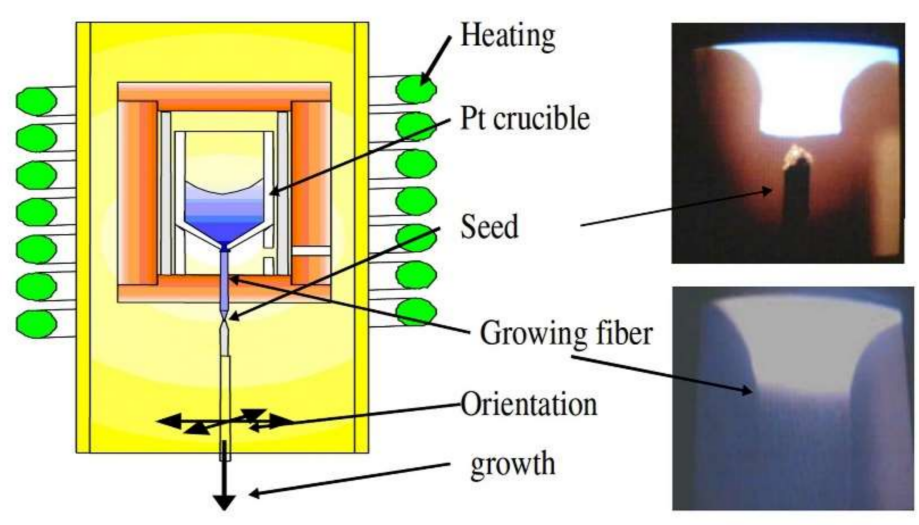

b

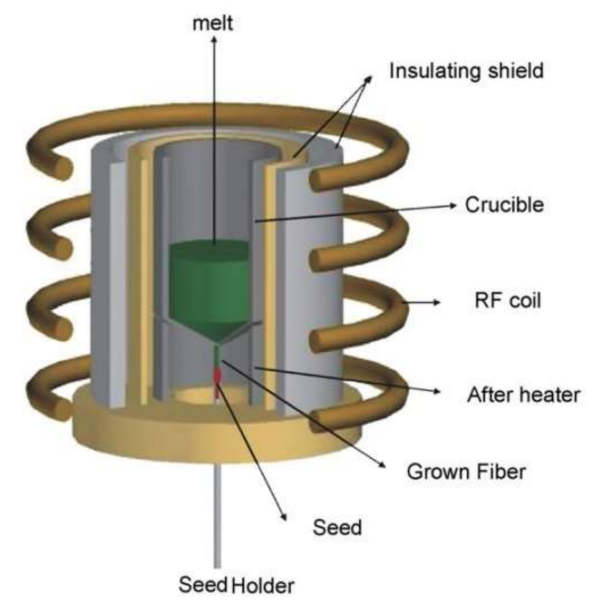

Figure 6. Schematic and photographs of micro pulling down set-up. (a,b) BGO and YAlO3 crystal fibers grown by micro pulling down technique. Reprinted with permission from ref. [91,99]. Copyright 2009 and 2007, Elsevier B.V.

However, the control process of $\mu$-PD and LHPG methods is complex. Many control parameters of systems, such as the heating temperature, the pulling speed, the cooling rate at the liquid/solid surface, and the stability of the system, affect the final quality and length of the grown single crystal. In addition, only specific materials can be prepared by these two methods. Therefore, the restricted material selection, slow crystallization rate, and stringent conditions make the $\mu$-PD and LHPG methods low in productivity, limiting their applications.

\subsection{Fiber Thermal Drawing Method}

Traditional optical fibers are fabricated by the thermal drawing process (Figure 7). First, the doped silica core and cladding are combined to form a macro preform with a diameter of tens of millimeters. Then, the preform is placed on the fiber drawing tower and fed into the heating furnace under a feed-in velocity. The glass preform is softened at high 
temperature and pulled into a fiber with micron diameter under external tension force. By adjusting the heating temperature, applied force, and pulling velocity, the diameter and mechanical properties of the as-drawn fibers can be precisely controlled.

a

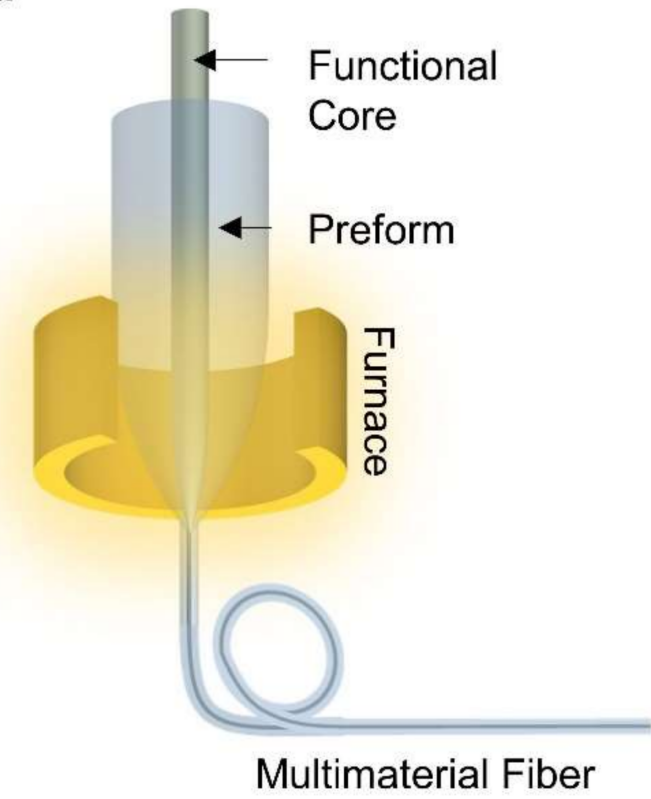

b

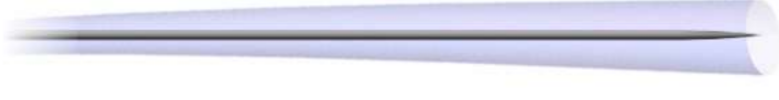

Multi-material Multi-functional Fiber

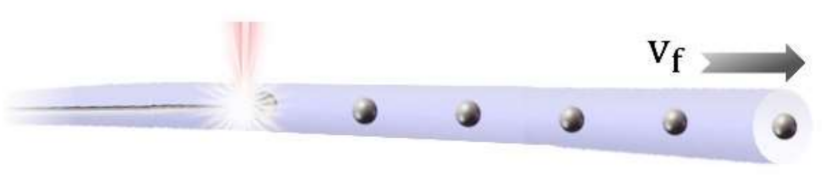

Microstructure Fabrication

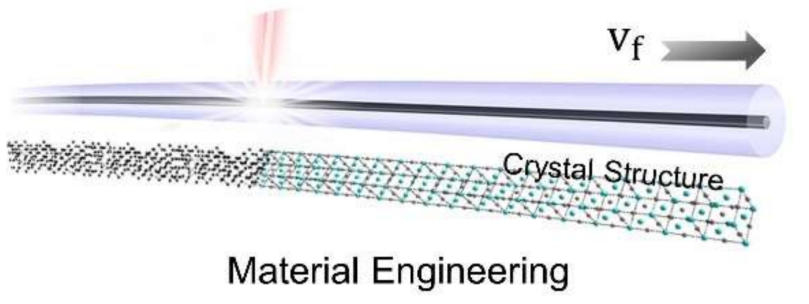

Figure 7. Schematic of multi-material fiber thermal drawing method and in-fiber thermal treatment processing. (a) Schematic of advanced fiber thermal drawing process. (b) In-fiber microstructure generation process and material engineering process.

The commonly used communication optical fibers are fabricated from silica glass and lightly doped silica glass. Recently, with the development of the fiber thermal drawing process and material engineering, the fiber fabrication process provides access to a wider range of materials. For example, this advanced fiber drawing method has embedded metals, semiconductors, chalcogenide glasses, and doped polymers into one multi-material multi-functional fiber, expanding applications of optical fibers to optoelectronic devices, flexible electronics, multiparameter sensing, as well as radiation monitoring.

Several promising attempts have been achieved to fabricate fiber radiation dosimeters based on intrinsic RIL and RIA effects. Without the need for extrinsic sensing units, the fiber thermal drawing process can draw the radiation-sensitive and scintillation materials into an optical fiber directly, with radiation sensing and monitoring capabilities. As shown in Figure 7a, the radiation-sensitive and scintillation materials, such as Ce-doped silica, and Li-enriched glass, are fabricated into the functional fiber core and inserted into the cladding tube to form the multi-material preform. The preform is then drawn into the scintillating fiber with a micron diameter and hundreds of meters in length. The fiber drawing process is accompanied by a large cooling rate and fast pulling velocity, resulting in amorphous or poly-crystalline structures for fiber core.

In 2018, Cove et al. achieved a cerium-doped sol-gel silica core fluorinated silica cladding fibers for high energy physics applications (Figure 8a). The Ce-doped preform, with a diameter of $10 \mathrm{~mm}$ and length of $70 \mathrm{~mm}$, are drawn into continuous and stable fibers at the heating temperature of $1900 \mathrm{~K}$ [68]. In 2019, Moore et al. fabricated Lienriched glass derived multicore scintillating fiber by the fiber thermal drawing process for neutron imaging applications. To increase the neutron detection efficiency, thousands of $6 \mathrm{Li}$ enriched silicate glass rods were hexagonally packed within the NKF9 glass tube cladding to form the multicore preform (Figure $8 b$ ). The single core diameter of as-drawn multicore fiber was $\sim 8.5 \mu \mathrm{m}$ and the proof-of-concept faceplate achieved a resolution of 
$\sim 16 \mu \mathrm{m}$ for neutron imaging [100]. In 2020, Lv et al. achieved a cerium-doped lutetiumyttrium-oxyorthosilicate (LYSO:Ce) core and silica cladding scintillating fiber by thermal drawing process (Figure $8 \mathrm{~d}$ ). The fiber preform has a diameter of $30 \mathrm{~mm}$ and was drawn at a temperature of $2100{ }^{\circ} \mathrm{C}$. The linear attenuation coefficient of the resulting scintillating fiber was 118 times higher than the conventional silica fiber as $68 \mathrm{keV}$. Based on similar principles and processes, Ce-doped silica, Pr-doped silica, Li-enriched glass and Tb-doped germanate glass and bismuth germanate glass fibers have been generated to achieve all-fiber radiation sensors with high sensitivity (Figure 8).

a

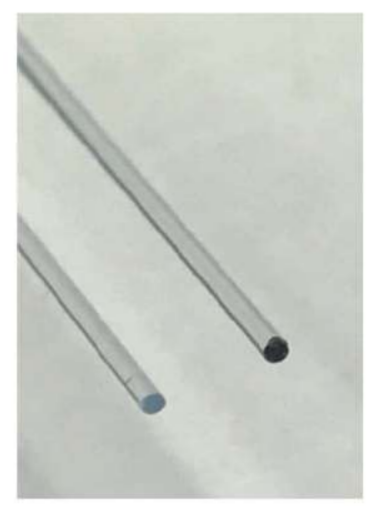

C

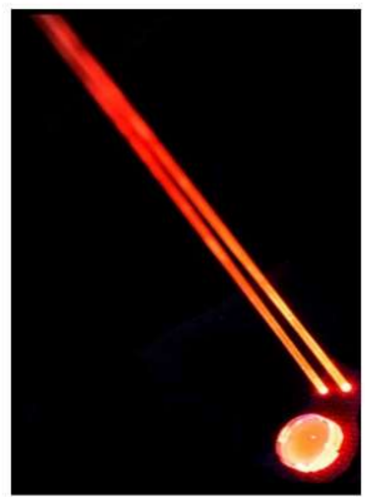

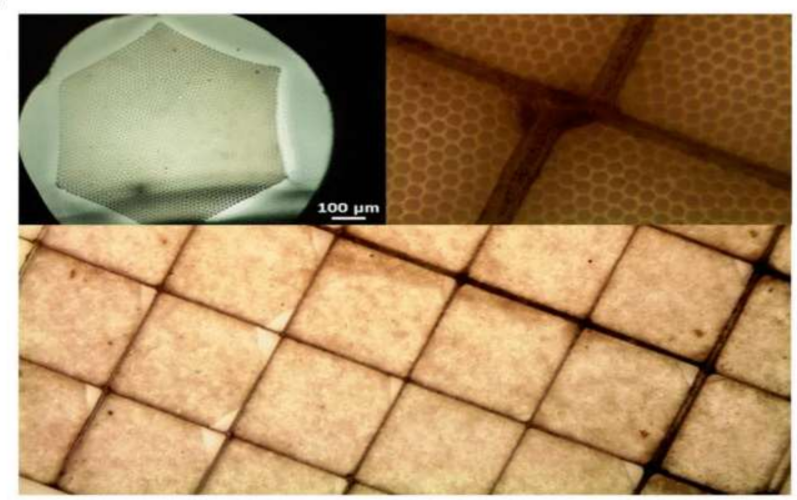

d

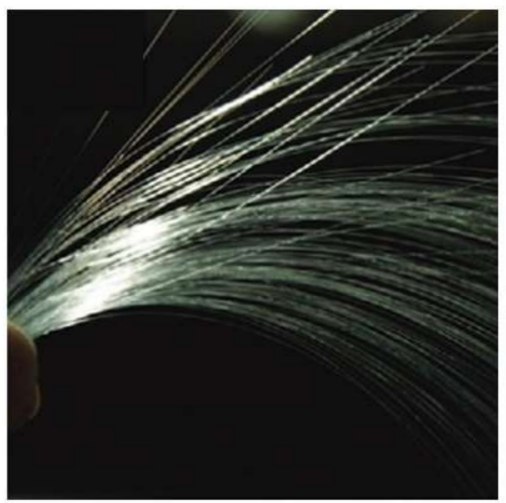

Figure 8. All-fiber radiation sensors. (a) $0.05 \%$ Ce-doped optical fibers before (on the left) and after 1 kGy irradiation (on the right). Reprinted with permissions from ref. [101]. Copyright 2018, Optical Society of America. (b) The cross-section of a Li-glass multicore fiber, and the polished faceplate surface of a multicore array. Reprinted with permissions from ref. [100]. Copyright 2019, IEEE. (c) Prdoped silica scintillating fibers and faceplate. Reprinted with permissions from ref. [70]. Copyright 2017, Elsevier B.V. (d) LYSO:Ce core silica cladding scintillating fibers. Reprinted with permissions from ref. [102]. Copyright 2020, WILEY-VCH Verlag GmbH \& Co. KGaA, Weinheim, Germany.

\subsection{Methods of In-fiber Microstructure Generation and Crystal Structure Modifications}

The as-drawn fibers fabricated from the fiber thermal drawing methods have a generally polycrystalline or amorphous crystal structure due to the fast drawing speed, which will hinder light transmission, carrier migration, and electrical conductivity of the optical fiber. With the development of the in-fiber processing technology, the thermal treatment processes are used in fiber to fabricate microstructure and modify the crystal structure (Figure 7b).

First, a heating source, such as micron tube, oxyhydrogen flame, and laser, is used to soften the fiber. As the cladding materials of fibers are glasses and polymers, they can maintain certain shapes while being softened, providing structural support for the melted fiber cores. The capillary instability will introduce a perturbation at the core/cladding liquid interface 
due to surface tension force and viscous forces. The development of the perturbation can lead the continuous fiber core to break up into micron and nanoparticles. These in-fiber generated microstructures can further cooperate with other structures in fiber to form multi-functional fibers [11,12,103-105]. This intriguing phenomenon prompts us with a new way to fabricate and design novel distributed radiation sensors [16]. For example, the optoelectrical fiber sensors with Ge-Pt and Ce-Cu sensing units (Figure 9) [16,102,106].

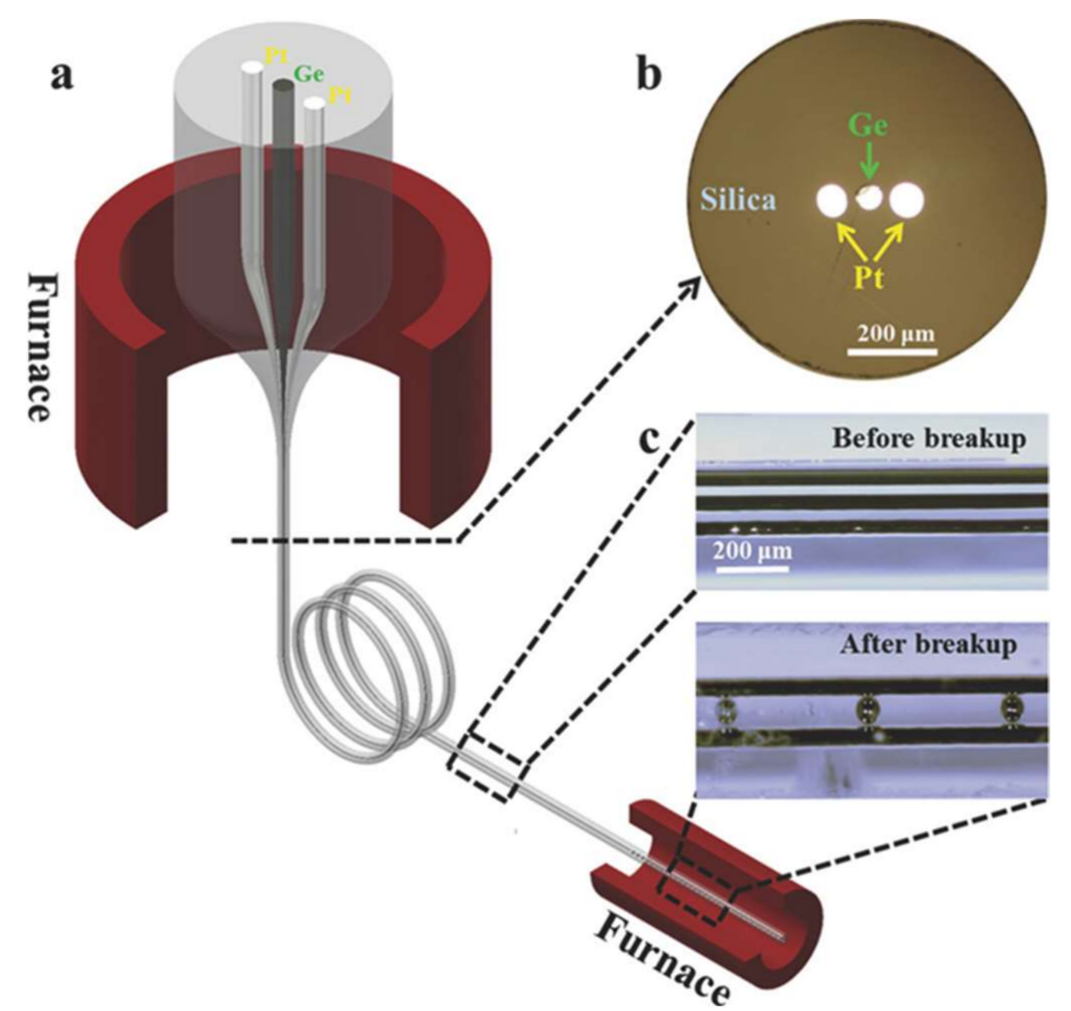

Figure 9. All-in-fiber germanium-platinum optoelectronic sensing units. (a) Multimaterial fiber drawn by fiber thermal drawing process. (b) Cross-section of germanium-platinum optoelectronic fiber. (c) Continuous germanium and platinum fiber cores (top, before breakup) and assembled germanium-platinum micron functional units by thermal induced in-fiber capillary instabilities (bottom, after breakup). Reprinted with permissions from ref. [106]. Copyright 2017, WILEY-VCH Verlag GmbH \& Co. KGaA, Weinheim, Germany.

Second, the in-fiber thermal treatment process has been proven to be effective for single crystal fiber fabrication. Similar to the LHPG and the laser floating zone (LFZ) methods, we can use a laser as a small and precisely controlled heating source to melt a limited zone of the fiber core. Then, the laser spot scans along with the fiber axial. The fiber core will be melted, resolidified, and recrystallized into single crystal at the liquid/solid interface. The crystal structure and orientation remain consistent throughout the whole fibers. This process should be careful to control some factors, such as laser moving velocity, heating temperature, as well as mechanical and thermal properties of cladding materials. Many single crystal optical fibers have been fabricated by these methods, including silicon, germanium, selenium, tellurium, and gallium antimonide optoelectrical fiber, etc. [12,15,107-113].

Therefore, the in-fiber thermal treatment process offers a new promising way to fabricate high-efficient single crystal radiation optical fibers with functional microstructures.

\section{Application}

Radiation dosimetry based on optical fibers is being used in many fields. Table 2 shows some mature and possible application fields of optical fiber radiation sensors, such as 
industry radiation monitoring, radiation monitoring in space, as well as medical radiation dosimetry. In this section, we will introduce some inspiring applications in detail.

Table 2. Applications of Optical Fiber Radiation Sensors.

\begin{tabular}{|c|c|c|c|}
\hline \multicolumn{2}{|c|}{ Application } & Ionizing Radiation & Refs \\
\hline \multirow{4}{*}{$\begin{array}{l}\text { Industry Radiation } \\
\text { Monitoring }\end{array}$} & $\begin{array}{l}\text { Food Irradiation } \\
\text { Dosimetry }\end{array}$ & X-ray, Gamma-ray & {$[114,115]$} \\
\hline & $\begin{array}{l}\text { Monitoring of Nuclear } \\
\text { Industry }\end{array}$ & & \\
\hline & $\begin{array}{ll}\text { - } & \text { Nuclear Waste } \\
\text { Storage } \\
\text { - } \quad \text { Nuclear Reactor Core }\end{array}$ & Gamma-ray & [116-120] \\
\hline & $\begin{array}{l}\text { Environmental } \\
\text { Monitoring }\end{array}$ & X-ray, Gamma-ray & [121] \\
\hline \multirow{2}{*}{$\begin{array}{c}\text { Radiation Monitoring in } \\
\text { Space }\end{array}$} & $\begin{array}{l}\text { Dosimetry for Spacecraft } \\
\text { Shall }\end{array}$ & X-ray, Gamma-ray & {$[20,122,123]$} \\
\hline & Radiation Monitoring & X-ray, Gamma-ray & [124-126] \\
\hline \multirow{3}{*}{$\begin{array}{l}\text { Medical Radiation } \\
\text { Dosimetry }\end{array}$} & $\begin{array}{l}\text { External Beam } \\
\text { Radiotherapy }\end{array}$ & $\begin{array}{l}\text { X-ray, Gamma-ray, } \\
\text { Proton beams }\end{array}$ & [127-133] \\
\hline & Brachytherapy & $\begin{array}{l}\text { X-ray, Gamma-ray, } \\
\text { Beta radiation }\end{array}$ & [134-138] \\
\hline & Diagnostic Radiology & X-ray, Gamma-ray & [139-142] \\
\hline
\end{tabular}

\subsection{Industrial Radiation Monitoring}

Optical fiber-based radiation sensors offer adequate sensitivity with their unique ability in distributed radiation measurement; they are small in size, intrinsically insensitive to magnetic fields and electromagnetic interference, and reasonable in cost. These features make them useful in several industrial applications. The fields for optical fiber-based radiation dosimeters to play an important role can be categorized into two types. Optical fiber-based radiation dosimeters are useful in large-scale environmental monitoring for mining plants, mineral processing facilities, and nuclear power plants, where the baseline radioactivity data must be monitored for safety concerns. Therefore, a large area containing a great number of points shall be measured, which is hardly accomplished by commercially available thermoluminescent dosimeters (TLD) due to the cost and manpower limitations, or for measurement in a moving product line. In 2017, Rozaila et al. conducted the assessment for the baseline radioactivity data off-site of a rare earth processing plant in Pahang, Malaysia (Figure 10a) [121]. A Ge-doped collapsed photonic crystal fiber was used as the fiber-form TLD and calibrated against commercially available TLD (TLD-200 and TLD-100). Doses in the range $0.5-10 \mathrm{mGy}$ of several elements were recorded and one point with the radiation higher than the guideline of UNSCEAR safety limit was identified (Figure 10b). For another industrial application, food irradiations for disinfestation, ripening delaying, elimination of pathogenic and spoilage bacteria are widely used today. A high dose of 1 $\mathrm{kGy}$ to $10 \mathrm{kGy}$ is delivered in the process, which, thus, raises concerns for the radioactive level on the food, which shall be monitored carefully to enhance consumer confidence. Tanjuddin et al. reported their work to develop optical fibers for food irradiation dosimeters. Ge-B doped optical fibers in different forms and sizes were characterized for their ability in radiation sensing at the kGy level. The linearity, reproducibility, and fading of data recorded by the fiber-based dosimeter give hopes for in-site dosimetry in the food processing line [121]. 
a
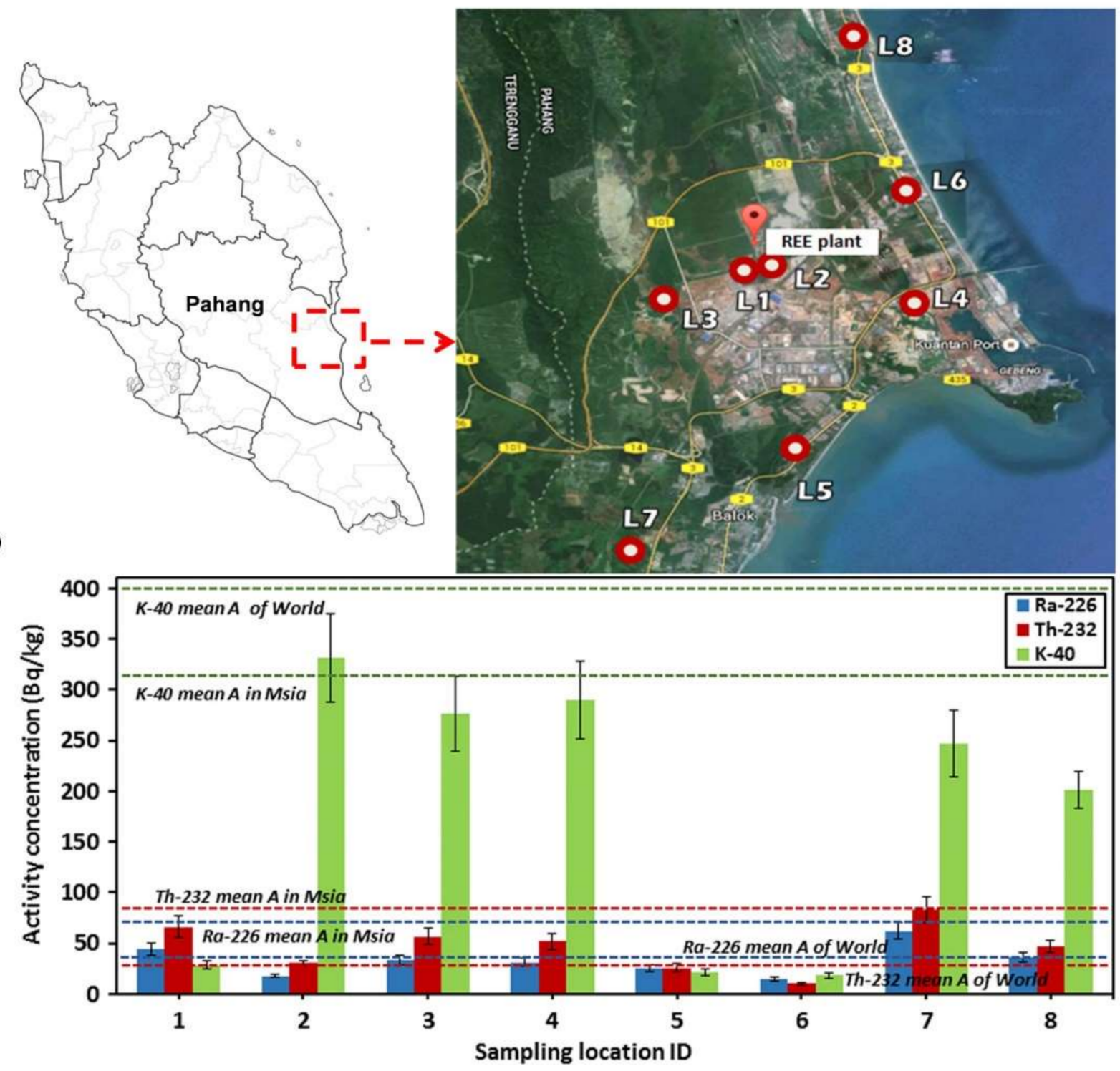

Figure 10. Environment monitoring by silica fiber-based thermoluminescence dosimetry. (a) Sampling locations off-site of the rare-earths processing facility, Pahang, Malaysia. (b) Activity concentration of elements recorded by the Ge-doped collapsed photonic crystal fiber. Reprinted with permissions from ref. [121]. Copyright 2017, IOP Publishing Ltd.

Another field for optical fiber-based radiation dosimeters to perform is working under extreme conditions, which could be too narrow, too zigzagged, or too dangerous for normal operations. Taking the nuclear power facility as an example, local dose deposition measurements and distributed hot-spots dose monitoring are strongly needed in the nuclear infrastructures, nuclear waste repositories, and the surrounding environment [143]. Optical fiber-based radiation dosimeters are powerful in this case by providing distributed sensors with radiation-tolerant of gamma total doses approaching 1 GGy and neutron doses of up to $1024 \mathrm{n} / \mathrm{m}^{2}$ (>0.1 MeV) [144]. Fernandez et al. investigated three optical fiber-based radiation sensors under intense gamma radiation. A fiber-coupled optically stimulated luminescence system, and a scintillation fiber-optic radiation monitoring system was tested for the real-time radiation monitoring at $\mathrm{Gy} / \mathrm{h}$ level doses rate. A commercial plastic fiber was also examined to measure the radiation with the threshold between 100-1000 Gy; the results showed that PMMA optical fiber can be used as the gamma 
dosimeter. All fiber-based radiation sensors have met most of the requirements from monitoring a thermonuclear facility [116].

\subsection{Radiation Monitoring in Space}

Monitoring high-energy cosmic rays is strongly needed in both manned and unmanned spacecraft for health concerns of astronauts and the normal function of the carried instruments. Indeed, dosimeters are also carried as a scientific payload to measure the cosmic rays. Differing from dosimeters used on earth, developing a dosimeter for spacecraft shall minimize the weight and volume as much as possible; they should be able to work normally under the total radiation doses of a few kGy, high vacuum, and extremely low temperature. Optical fiber-based radiation dosimeters have been considered for use in space, because they can be fully embedded in satellite structures to provide a wide field of detection with little impact on the host satellite. The Navigation Technology Satellite 2 (NTS-2) was launched in 1977 carrying a glass fiber as the dosimeter, which firstly illustrated the feasibility based on the darkening of glass (Figure 11a). The system recorded doses of $0.35,6$, and 60 Gy under different aluminum shielding, 367 days after launch [145]. Los Alamos National Laboratory reported two space fiber-optic X-ray burst detectors designed for the STEP mission 3 spacecraft. The first one was made of a $500 \mu \mathrm{m}$ (diameter) $\times 4 \mathrm{~m}$ (long) scintillating fiber coupled to a silicon photodiode and the second one was a $100 \mu \mathrm{m}$ core $\times 1.25 \mathrm{~m}$ long multimode Ge-doped silica fiber, which worked based on the radiation darkening phenomenon. The scintillating fiber gave a fast signal for timing and the Ge-doped fiber darkened for a few milliseconds after a burst of X-ray. The coincidence of two signals represented an occurrence of an X-ray burst [146]. Terasawa et al. developed a camera made of a scintillating fiber stack for dosimetry in spacecraft. The camera was able to identify charged particles, neutrons, and gamma-rays in three dimensions (Figure 11b). Especially for neutron dosimetry, the smaller size of fiber helped the reduction of threshold [147]. Most recently, iXblue deployed two several-kilometer-long optical fibers as active dosimeters to measure ionizing radiation in the international space station in 2021, and the first result is waiting for further announcement [148].

a

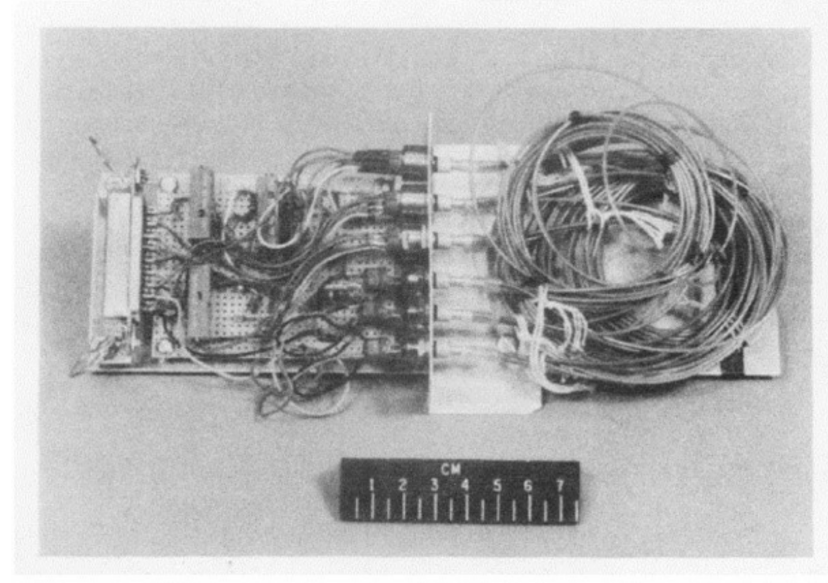

b

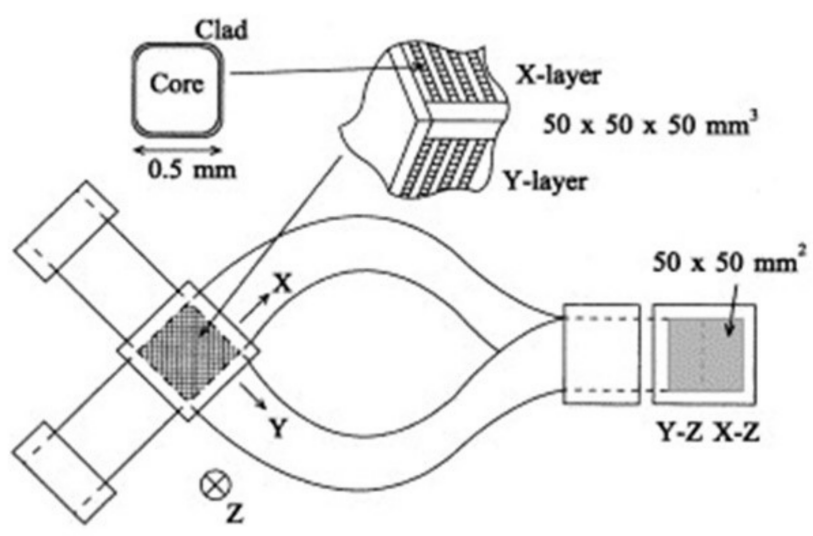

Figure 11. The optical fiber radiation dosimeter for radiation monitoring in space. (a) Testbed with sensing fibers for NST-2 mission. Reprinted with permissions from ref. [145]. Copyright 1969, IEEE. (b) Structure of a scintillating fiber stack. Reprinted with permissions from ref. [147]. Copyright 2001, Elsevier Science B.V.

\subsection{Medical Applications}

Optical fiber-based radiation dosimeters play a unique role in radiotherapies majorly due to their ability in high-resolution dose mapping. Before the patient undergoes ra- 
diotherapies, accurately evaluating the dose at each point is necessary for designing the treatment plan. Especially for an advanced delivery technique such as intensity modulated radiation therapy (IMRT), in which the dose calculation is more complex. Among numerous materials used for medical radiation dosimetry, thermoluminescent (TL) silica optical fibers have attracted attention for their high spatial resolution, small size, water and corrosion proof, and reasonable cost. Noor et al. demonstrated an in vitro study by using a commercial TL Ge-doped silica fiber for IMRT dose mapping in three dimensions. The fiber verified high and low dose regions in the treatment planning system for $6 \mathrm{MV}$ and $15 \mathrm{MV}$ normal photon energy, and the result showed good agreement with the conventional $\mathrm{LiF}$ thermoluminescent dosimeters (Figure 12) [132]. Another study conducted by Issa et al. demonstrated the feasibility of using Ge-doped silica optical fiber for brachytherapy source dosimetry. The fiber offered a sub-mm spatial resolution, a linear response from $10 \mathrm{cGy}$ to $>1 \mathrm{kGy}$, and dose-rate independence. The measurement data showed good agreement to simulations and dose mapping of the treatment planning system [136].

a

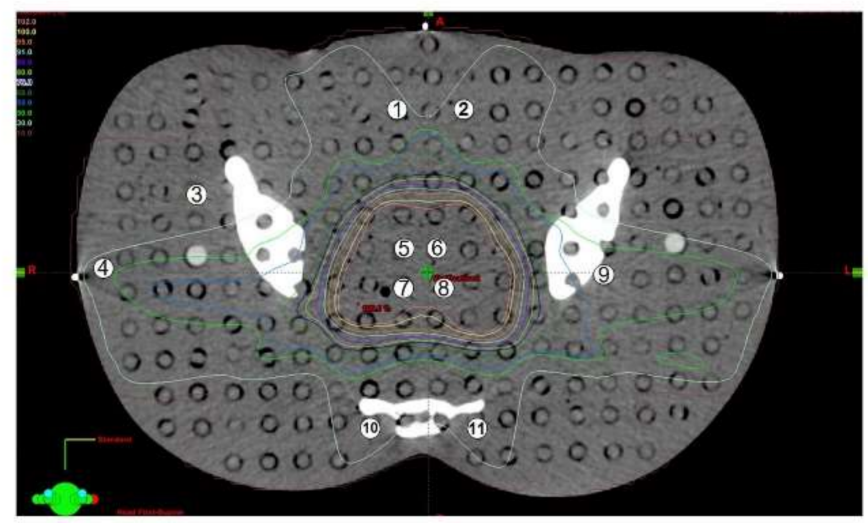

b

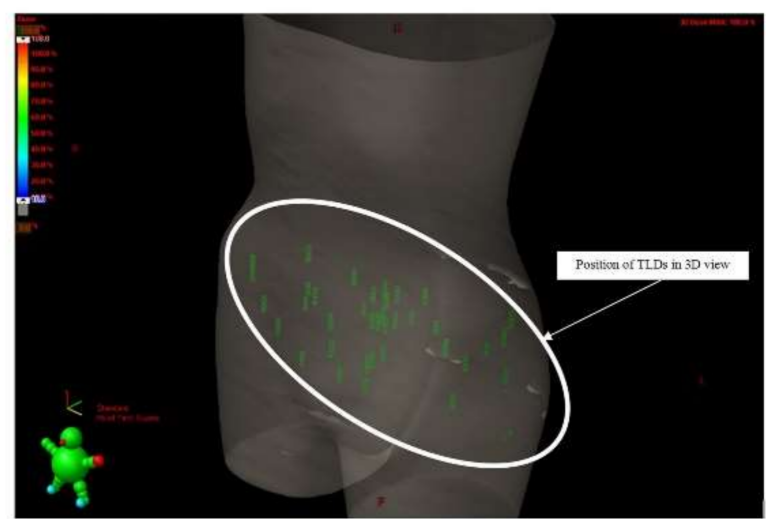

Figure 12. Ge-doped optical fiber for in-vitro. (a) Ge-doped optical fibers and LiF TLDs (highlighted) in $3 \mathrm{D}$ view. (b) Numbers correspond to the positions of Ge-doped optical fibers and LiF TLDs in a Rando-phantom CT slice. Reprinted with permissions from ref. [132]. Copyright 2010, Elsevier B.V.

\section{Conclusion and Outlook}

In this review, we discuss the current state of optical fiber-based radiation sensors, including extrinsic sensors that rely on extrinsic materials and structures as sensing units, as well as intrinsic fiber sensors that take fiber as sensing units. The basic sensing principles of fiber-based radiation sensors were introduced. The underlying mechanism and actual phenomena of RIL, RIA, and RI-GWS were presented. Various sensor structures based on different sensing principles were also summarized. Meanwhile, the fabrication processes of the intrinsic fiber radiation sensor were introduced. The single crystal scintillating fiber can be fabricated from the micro pulling down process and laser heating pedestal growth. The advanced multi-material scintillating fibers can be drawn directly based on the fiber drawing process. Further in-fiber microstructure generation and crystal structure modifications were also introduced. In addition, various applications were reviewed, including radiation monitoring in industry and space, industrial radiation process, and medical treatment and monitoring. The fiber-based radiation sensors can measure radiation doses from $\mu \mathrm{Gy}$ to $\mathrm{kGy}$, covering a large spatial scale with high resolution. They also can be bundled to form a sensing faceplate for radiographic imaging with micron pixels.

Despite the promising advantages in applications, optical fiber-based radiation sensors still have room for improvement. The optical fiber sensing for radiation is sometimes nonlinear, which will affect the calibration of specific radiation values and the monitoring accuracy. In addition, the measurement results are not decided by the radiation intensity alone. Other environmental factors, such as temperature, humidity, and external pressure, 
can all have an impact on the final detection result. The decoupling of the different influencing factors needs to be further investigated. Meanwhile, the spatial and temporal resolution of optical fiber based radiation sensors also needs to be further improved and optimized.

For future development, we offer some possible options. First, the uniformity of fabrication process and testing standard of fiber-based radiation sensors needs to be established. Past studies have shown that the sensing performance shows variability even for two fibers of the same type from the same company [81]. The fiber fabrication tolerance is the main reason for this difference. Meanwhile, the fabrication of FBGs and LPGs also introduces some slight differences in grating periods, which will further disrupt the uniformity of the fiber-based radiation sensor performance. On the other hand, there is no uniform method or standard for radiation testing. Many environmental factors can be coupled with the radiation testing results, further affecting the accuracy. Nowadays, there have been many attempts to improve the accuracy and repeatability of calibration testing. Second, distributed optical fiber sensors (DOFS) are a tremendously advantageous application of fiber optic sensing $[149,150]$. DOFS can provide dense and accurate sampling points over long distances at a low cost. The distributed acoustic sensor (DAS), and distributed temperature sensor (DTS) have been used widely in practice for seismic monitoring, geothermal sensing, building quality monitoring, and other fields. Several existing fiber-based radiation sensing technologies have the potential for distributed sensing. The broad application prospects of distributed radiation sensors (DRS) make it a worthy direction for development to improve the spatial and temporal resolution of the optical fiber radiation sensors. Last, the multi-material multi-functional fibers are a new and promising way for optical fiber-based radiation sensors. From one side, the abundance of fiber optic coating and encapsulation materials can provide additional sensing mechanisms. Rather than optical effects, the sensing mechanisms based on the fiber coating, such as optoelectric effect and track elastic effect, can offer more solutions [151]. On another side, with the advanced fiber thermal drawing process, plenty of materials, not just traditional optical fiber materials, could be drawn into the fiber shapes, providing more suitable materials for radiation sensing. Meanwhile, the multi-material optical fibers can be fabricated with different materials together into one fiber, including but not limited to optical materials, thermoelectric materials, and piezoelectric materials. This composite of materials and functions shows a direction for the signal decoupling.

Author Contributions: Conceptualization and idea, L.W., S.C.T., and J.Z.; literature research, Y.X., C.W., and Y.C.; preparation of tables and figures, Y.X., and C.W.; writing-original draft preparation, J.Z.; writing-review and editing, L.W., and S.C.T. All authors have read and agreed to the published version of the manuscript.

Funding: This work was supported by Fundamental Research Funds for the Central Universities, China University of Geosciences (Wuhan) (162301212322); the Singapore Ministry of Education Academic Research Fund Tier 2 (MOE2019-T2-2-127 and MOE-T2EP50120-0002), A * STAR under AME IRG (A2083c0062), the Singapore Ministry of Education Academic Research Fund Tier 1 (MOE2019T1-001-103 (RG 73/19) and MOE2019-T1-001-111 (RG90/19)), and the Singapore National Research Foundation Competitive Research Program (NRF-CRP18-2017-02). This work was also supported by Nanyang Technological University.

Institutional Review Board Statement: Not applicable.

Informed Consent Statement: Not applicable.

Data Availability Statement: Not applicable.

Conflicts of Interest: The authors declare no conflict of interest. 


\section{References}

1. Dartnell, L.R. Ionizing Radiation and Life. Astrobiology 2011, 11, 551-582. [CrossRef] [PubMed]

2. Cortez, R.A.; Papageorgiou, X.; Tanner, H.G.; Klimenko, A.V.; Borozdin, K.N.; Lumia, R.; Priedhorsky, W.C. Smart Radiation Sensor Management. IEEE Robot. Autom. Mag. 2008, 15, 85-93. [CrossRef]

3. Henschel, H.; Köhn, O.; Schmidt, H.U. Optical Fibres as Radiation Dosimeters. Nucl. Instrum. Methods Phys. Res. Sect. B Beam Interact. Mater. At. 1992, 69, 307-314. [CrossRef]

4. Lin, Z.; Lv, S.; Yang, Z.; Qiu, J.; Zhou, S. Structured Scintillators for Efficient Radiation Detection. Adv. Sci. 2022, 9, 2102439. [CrossRef] [PubMed]

5. Bueker, H.; Haesing, F.W. Fiber Optic Radiation Sensors. In Proceedings of the Optical Fibre Sensing and Systems in Nuclear Environments, Mol, Belgium, 30 December 1994.

6. Zubair, H.T.; Begum, M.; Moradi, F.; Rahman, A.K.M.M.; Mahdiraji, G.A.; Oresegun, A.; Louay, G.T.; Omar, N.Y.M.; Khandaker, M.U.; Adikan, F.R.M.; et al. Recent Advances in Silica Glass Optical Fiber for Dosimetry Applications. IEEE Photonics J. 2020, 12, 1-25. [CrossRef]

7. Girard, S.; Morana, A.; Ladaci, A.; Robin, T.; Mescia, L.; Bonnefois, J.-J.; Boutillier, M.; Mekki, J.; Paveau, A.; Cadier, B.; et al Recent Advances in Radiation-Hardened Fiber-Based Technologies for Space Applications. J. Opt. 2018, 20, 093001. [CrossRef]

8. Girard, S.; Alessi, A.; Richard, N.; Martin-Samos, L.; de Michele, V.; Giacomazzi, L.; Agnello, S.; Francesca, D.D.; Morana, A.; Winkler, B.; et al. Overview of Radiation Induced Point Defects in Silica-based Optical Fibers. Rev. Phys. 2019, 4, 100032. [CrossRef]

9. Francesca, D.D.; Toccafondo, I.; Vecchi, G.L.; Calderini, S.; Girard, S.; Alessi, A.; Ferraro, R.; Danzeca, S.; Kadi, Y.; Brugger M. Distributed Optical Fiber Radiation Sensing in the Proton Synchrotron Booster at CERN. IEEE Trans. Nucl. Sci. 2018, 65, 1639-1644. [CrossRef]

10. Tao, G.; Abouraddy, A.F. Multimaterial Fibers: A New Concept in Infrared Fiber Optics. In Proceedings of the Fiber Optic Sensors and Applications XI, SPIE Sensing Technology + Applications, Baltimore, MD, USA, 18 June 2014.

11. Kaufman, J.J.; Ottman, R.; Tao, G.; Shabahang, S.; Banaei, E.H.; Liang, X.; Johnson, S.G.; Fink, Y.; Chakrabarti, R.; Abouraddy, A.F. In-Fiber Production of Polymeric Particles for Biosensing and Encapsulation. Proc. Natl. Acad. Sci. USA 2013, 110, 15549-15554. [CrossRef] [PubMed]

12. Zhang, J.; Wang, Z.; Wang, Z.; Wei, L. Advanced Multi-Material Optoelectronic Fibers: A Review. J. Lightwave Technol. 2021, 39, 3836-3845. [CrossRef]

13. Wang, W.C.; Zhou, B.; Xu, S.H.; Yang, Z.M.; Zhang, Q.Y. Recent Advances in Soft Optical Glass Fiber and Fiber Lasers. Prog. Mater. Sci. 2019, 101, 90-171. [CrossRef]

14. Yan, W.; Page, A.; Nguyen-Dang, T.; Qu, Y.; Sordo, F.; Wei, L.; Sorin, F. Advanced Multimaterial Electronic and Optoelectronic Fibers and Textiles. Adv. Mater. 2019, 31, 1802348. [CrossRef] [PubMed]

15. Yan, W.; Nguyen-Dang, T.; Cayron, C.; Gupta, T.D.; Page, A.G.; Qu, Y.; Sorin, F. Microstructure Tailoring of Selenium-Core Multimaterial Optoelectronic Fibers. Opt. Mater. Express 2017, 7, 1388-1397. [CrossRef]

16. Dai, Y.; Du, M.; Feng, X.; Zhang, W.; Zhou, S. Microstructured Multimaterial Fibers for Efficient Optical Detection. J. Am. Ceram. Soc. 2021, 104, 4058-4064. [CrossRef]

17. Healy, N.; Mailis, S.; Bulgakova, N.M.; Sazio, P.J.; Day, T.D.; Sparks, J.R.; Cheng, H.Y.; Badding, J.V.; Peacock, A.C. Extreme Electronic Bandgap Modification in Laser-Crystallized Silicon Optical Fibres. Nat. Mater. 2014, 13, 1122-1127. [CrossRef] [PubMed]

18. Sorin, F.; Abouraddy, A.F.; Orf, N.; Shapira, O.; Viens, J.; Arnold, J.; Joannopoulos, J.D.; Fink, Y. Multimaterial Photodetecting Fibers: A Geometric and Structural Study. Adv. Mater. 2007, 19, 3872-3877. [CrossRef]

19. Yamamoto, S.; Aoki, I.; Higashi, T. Optical Fiber-Based ZnS(Ag) Detector for Selectively Detecting Alpha Particles. Appl. Radiat. Isot. 2021, 169, 109495. [CrossRef]

20. Pheron, X.; Girard, S.; Boukenter, A.; Brichard, B.; Delepine-Lesoille, S.; Bertrand, J.; Ouerdane, Y. High $\gamma$-Ray Dose Radiation Effects on the Performances of Brillouin Scattering Based Optical Fiber Sensors. Opt. Express 2012, 20, 26978-26985. [CrossRef]

21. O'Keeffe, S.; Fernandez, A.F.; Fitzpatrick, C.; Brichard, B.; Lewis, E. Real-Time Gamma Dosimetry Using Pmma Optical Fibres for Applications in the Sterilization Industry. Meas. Sci. Technol. 2007, 18, 3171-3176. [CrossRef]

22. Fernandez, A.F.; Gusarov, A.; Brichard, B.; Decréton, M.; Berghmans, F.; Mégret, P.; Delchambre, A. Long-Term Radiation Effects on Fibre Bragg Grating Temperature Sensors in a Low Flux Nuclear Reactor. Meas. Sci. Technol. 2004, 15, 1506-1511. [CrossRef]

23. Kertzscher, G.; Beddar, S. Ruby-Based Inorganic Scintillation Detectors for 192Ir Brachytherapy. Phys. Med. Biol. 2016, 61, 7744-7764. [CrossRef] [PubMed]

24. Kertzscher, G.; Beddar, S. Inorganic Scintillation Detectors for 192Ir Brachytherapy. Phys. Med. Biol. 2019, 64, 225018. [CrossRef] [PubMed]

25. Teichmann, T.; Sommer, M.; Henniger, J. Dose Rate Measurements with a Ruby-Based Fiber Optic Radioluminescent Probe. Radiat. Meas. 2013, 56, 347-350. [CrossRef]

26. Belley, M.D.; Craciunescu, O.; Chang, Z.; Langloss, B.W.; Stanton, I.N.; Yoshizumi, T.T.; Therien, M.J.; Chino, J.P. Real-Time Dose-Rate Monitoring with Gynecologic Brachytherapy: Results of an Initial Clinical Trial. Brachytherapy 2018, 17, 1023-1029. [CrossRef] 
27. Molina, P.; Sommer, M.; Kattner, F.; Henniger, J. Response Characterization of an $\mathrm{Y}_{2} \mathrm{O}_{3}$ :Eu-Based Radioluminescence Probe Under $\mathrm{Co}^{-60}$ Irradiation. Radiat. Meas. 2013, 56, 338-341. [CrossRef]

28. Jang, K.W.; Cho, D.H.; Yoo, W.J.; Seo, J.K.; Heo, J.Y.; Park, J.Y.; Lee, B. Fiber-Optic Radiation Sensor for Detection of Tritium. Nucl. Instrum. Methods Phys. Res. Sect. A Accel. Spectrometers Detect. Assoc. Equip. 2011, 652, 928-931. [CrossRef]

29. Wu, Z.; Zaghloul, M.A.S.; Carpenter, D.; Li, M.J.; Daw, J.; Mao, Z.H.; Hnatovsky, C.; Mihailov, S.J.; Chen, K.P. Mitigation of Radiation-Induced Fiber Bragg Grating (FBG) Sensor Drifts in Intense Radiation Environments Based on Long-Short-Term Memory (LSTM) Network. IEEE Access 2021, 9, 148296-148301. [CrossRef]

30. Venketeswaran, A.; Lalam, N.; Wuenschell, J.; Ohodnicki, P.R., Jr.; Badar, M.; Chen, K.P.; Lu, P.; Duan, Y.; Chorpening, B.; Buric, M. Recent Advances in Machine Learning for Fiber Optic Sensor Applications. Adv. Intell. Syst. 2011, 4, 2100067. [CrossRef]

31. Madden, L.; Archer, J.; Li, E.; Wilkinson, D.; Rosenfeld, A. Temporal Separation of Cerenkov Radiation and Scintillation Using a Clinical LINAC and Artificial Intelligence. Phys. Med. Biol. 2018, 63, 225004. [CrossRef]

32. Cohen, A.J. Neutron Specific Color Center in Fused Silica and an Impurity Band of Identical Wavelength. Phys. Rev. 1957, 105, 1151. [CrossRef]

33. Amossov, A.; Rybaltovsky, A. Radiation Color Center Formation in Silica Glasses: A Review of Photo-and Thermo-Chemical Aspects of the Problem. J. Non-Cryst. Solids 1994, 179, 226-234. [CrossRef]

34. Griscom, D.L. A Minireview of the Natures of Radiation-Induced Point Defects in Pure and Doped Silica Glasses and Their Visible/Near-IR Absorption Bands, with Emphasis on Self-Trapped Holes and How They Can Be Controlled. Phys. Res. Int. 2013, 2013, 379041. [CrossRef]

35. Griscom, D.L. Nature of Defects and Defect Generation in Optical Glasses. Radiat. Eff. Opt. Mater. 1985, 541, 38-59.

36. Gusarov, A.; Hoeffgen, S.K. Radiation Effects on Fiber Gratings. IEEE Trans. Nucl. Sci. 2013, 60, 2037-2053. [CrossRef]

37. Friebele, E.; Gingerich, M.; Griscom, D. Survivability of Optical Fibers in Space. In Proceedings of the Optical Materials Reliability and Testing: Benign and Adverse Environments, Boston, MA, USA, 25 February 1993; pp. 177-188.

38. Oughstun, K.E.; Cartwright, N.A. On the Lorentz-Lorenz Formula and the Lorentz Model of Dielectric Dispersion. Opt. Express 2003, 11, 1541-1546. [CrossRef] [PubMed]

39. Lucarini, V.; Saarinen, J.J.; Peiponen, K.E.; Vartiainen, E.M. Kramers-Kronig Relations in Optical Materials Research; Springer Science \& Business Media: Berlin, Germany, 2005; Volume 110, p. 162. ISBN 3540236732/9783540236733.

40. Friebele, E.; Askins, C.; Gingerich, M.; Long, K. Optical Fiber Waveguides in Radiation Environments, II. Nucl. Instrum. Methods Phys. Res. Sect. B: Beam Interact. Mater. At. 1984, 1, 355-369. [CrossRef]

41. Girard, S.; Keurinck, J.; Boukenter, A.; Meunier, J.; Ouerdane, Y.; Azais, B.; Charre, P.; Vie, M. Gamma-Rays and Pulsed X-Ray Radiation Responses of Nitrogen-, Germanium-Doped and Pure Silica Core Optical Fibers. Nucl. Instrum. Methods Phys. Res. Sect. B Beam Interact. Mater. At. 2004, 215, 187-195. [CrossRef]

42. Morana, A.; Campanella, C.; Marin, E.; Melin, G.; Robin, T.; Vecchi, G.L.; di Francesca, D.; Boukenter, A.; Ouerdane, Y.; Mady, F.; et al. Operating Temperature Range of Phosphorous-Doped Optical Fiber Dosimeters Exploiting Infrared Radiation-Induced Attenuation. IEEE Trans. Nucl. Sci. 2021, 68, 906-912. [CrossRef]

43. Di Francesca, D.; Vecchi, G.L.; Girard, S.; Alessi, A.; Reghioua, I.; Boukenter, A.; Ouerdane, Y.; Kadi, Y.; Brugger, M. RadiationInduced Attenuation in Single-Mode Phosphosilicate Optical Fibers for Radiation Detection. IEEE Trans. Nucl. Sci. 2018, 65, 126-131. [CrossRef]

44. Li Vecchi, G.; di Francesca, D.; Sabatier, C.; Girard, S.; Alessi, A.; Guttilla, A.; Robin, T.; Kadi, Y.; Brugger, M. Infrared Radiation Induced Attenuation of Radiation Sensitive Optical Fibers: Influence of Temperature and Modal Propagation. Opt. Fiber Technol. 2020, 55, 102166. [CrossRef]

45. Regnier, E.; Flarnmer, I.; Girard, S.; Gooijer, F.; Achten, F.; Kuyt, G. Low-Dose Radiation-Induced Attenuation at Infrared Wavelengths for p-Doped, Ge-Doped and Pure Silica-Core Optical Fibres. IEEE Trans. Nucl. Sci. 2007, 54, 1115-1119. [CrossRef]

46. Alessi, A.; Guttilla, A.; Agnello, S.; Sabatier, C.; Robin, T.; Barnini, A.; di Francesca, D.; Vecchi, G.L.; Cannas, M.; Boukenter A.; et al. Near-IR Radiation-Induced Attenuation of Aluminosilicate Optical Fibers. Phys. Status Solidi A Appl. Mater. Sci. 2021, 218, 2000807. [CrossRef]

47. Kovacevic, M.S.; Savovic, S.; Djordjevich, A.; Bajic, J.; Stupar, D.; Kovacevic, M.; Simic, S. Measurements of Growth and Decay of Radiation Induced Attenuation During the Irradiation and Recovery of Plastic Optical Fibres. Opt. Laser Technol. 2013, 47, 148-151. [CrossRef]

48. Stajanca, P.; Krebber, K. Radiation-Induced Attenuation of Perfluorinated Polymer Optical Fibers for Radiation Monitoring. Sensors 2017, 17, 1959. [CrossRef] [PubMed]

49. Jiang, C.; Kuzyk, M.G.; Ding, J.-L.; Johns, W.E.; Welker, D.J. Fabrication and Mechanical Behavior of Dye-Doped Polymer Optical Fiber. J. Appl. Phys. 2002, 92, 4-12. [CrossRef]

50. Peters, K. Polymer Optical Fiber Sensors-A Review. Smart Mater. Struct. 2010, 20, 013002. [CrossRef]

51. Stajanca, P.; Krebber, K. Towards on-line Radiation Monitoring with Perfluorinated Polymer Optical Fibers. In Proceedings of the 2017 25th Optical Fiber Sensors Conference (OFS), Jeju, Korea, 29 June 2017.

52. Oresegun, A.; Basaif, A.; Tarif, Z.H.; Abdul-Rashid, H.A.; Hashim, S.A.; Bradley, D.A. Radioluminescence of Silica Optical Fibre Scintillators for Real-time Industrial Radiation Dosimetry. Radiat. Phys. Chem. 2021, 188, 109684. [CrossRef]

53. Keeffe, S.O.; Woulfe, P.; Sullivan, F.J. Radioluminescence Based Optical Fibre Sensor for Radiation Monitoring During Brachytherapy. In Proceedings of the 2015 IEEE SENSORS, Busan, Korea, 1-5 November 2015. 
54. Rodriguez, M.; Denis, G.; Akselrod, M.; Underwood, T.; Yukihara, E. Thermoluminescence, Optically Stimulated Luminescence and Radioluminescence Properties of $\mathrm{Al}_{2} \mathrm{O}_{3}$ : C, Mg. Radiat. Meas. 2011, 46, 1469-1473. [CrossRef]

55. Bhatt, B.C. Thermoluminescence, Optically Stimulated Luminescence and Radiophotoluminescence Dosimetry: An Overall Perspective. Radiat. Prot. Environ. 2011, 34, 6-16.

56. McKeever, S. Optically Stimulated Luminescence: A Brief Overview. Radiat. Meas. 2011, 46, 1336-1341. [CrossRef]

57. Gaza, R.; McKeever, S.W.S. A Real-Time, High-Resolution Optical Fibre Dosemeter Based on Optically Stimulated Luminescence (OSL) of KBr: Eu, for Potential Use During the Radiotherapy of Cancer. Radiat. Prot. Dosim. 2006, 120, 14-19. [CrossRef] [PubMed]

58. Qin, Z.; Hu, Y.S.; Ma, Y.; Zhao, W.H.; Sun, W.M.; Zhang, D.X.; Chen, Z.Y.; Elfed, L. Embedded Structure Fiber-optic Radiation Dosimeter for Radiotherapy Applications. Opt. Express 2016, 24, 5172-5185.

59. McCarthy, D.; O’Keeffe, S.; Lewis, E.; Sporea, D.G.; Sporea, A.; Tiseanu, I.; Woulfe, P.; Cronin, J. Radiation Dosimeter Using an Extrinsic Fiber Optic Sensor. IEEE Sens. J. 2014, 14, 673-685. [CrossRef]

60. Penner, C.; Hoehr, C.; O’Keeffe, S.; Woulfe, P.; Duzenli, C. Characterization of a Terbium-Activated Gadolinium Oxysulfide Plastic Optical Fiber Sensor in Photons and Protons. IEEE Sens. J. 2018, 18, 1513-1519. [CrossRef]

61. Li, D.Y.; Li, H.; Niu, M.Q.; Wan, C.L.; Lv, J.W.; Zhang, X.D. High Spatial Resolution Cold Neutron Imaging with $\mathrm{New}^{\mathrm{T} b^{3+}} / \mathrm{Ce}^{3+}$ Co-Doped $\mathrm{Gd}_{2} \mathrm{O}_{3}$ Scintillation Glass Fiber Arrays. Nucl. Instrum. Methods Phys. Res. Sect. A Accel. Spectrometers Detect. Assoc. Equip. 2020, 949, 162829. [CrossRef]

62. Kadari, A.; Refaei, A.; Saeed, M.A. Experimental and Theoretical Study of the TL Process in $\mathrm{Nd}^{3+}-\mathrm{Doped} \mathrm{SiO}_{2}$ Optical Fibers. Appl. Phys. A Mater. Sci. Process. 2019, 125, 639. [CrossRef]

63. Begum, M.; Rahman, A.K.M.M.; Abdul-Rashid, H.A.; Yusoff, Z.; Begum, M.; Mat-Sharif, K.A.; Amin, Y.M.; Bradley, D.A Thermoluminescence Characteristics of Ge-Doped Optical Fibers with Different Dimensions for Radiation Dosimetry. Appl. Radiat. Isot. 2015, 100, 79-83. [CrossRef]

64. Moradi, F.; Mandiraji, G.A.; Dermosesian, E.; Khandaker, M.U.; Mung, N.M.; Adikan, F.R.M.; Amin, Y.M. Influence of Dose History on Thermoluminescence Response of Ge-Doped Silica Optical Fibre Dosimeters. Radiat. Phys. Chem. 2017, 134, 62-70. [CrossRef]

65. Ramli, A.T.; Bradley, D.A.; Hashim, S.; Wagiran, H. The Thermoluminescence Response of Doped SiO $2 \mathrm{O}$ Ptical Fibres Subjected to Alpha-Particle Irradiation. Appl. Radiat. Isot. 2009, 67, 428-432. [CrossRef]

66. Hassan, M.F.; Rahman, W.N.W.A.; Kadir, A.B.A.; Isa, N.M.; Tominaga, T.; Geso, M.; Akasaka, H.; Bradley, D.A.; Noor, N.M. Fabricated Ge-Doped Flat Optical Fibres: Assessing the Thermoluminescence Glow Curves for Proton Beam Irradiation. AIP Conf. Proc. 2018, 2045, 020084.

67. Moradi, F.; Mandiraji, G.A.; Khandaker, M.U.; Ung, N.M.; Adikan, F.R.M.; Khellaf, I.; Bradley, D.A. Investigation on Various Types of Silica Fibre as Thermoluminescent Sensors for Ultra-High Dose Radiation Dosimetry. Sens. Actuators A Phys. 2018, 273, 197-205. [CrossRef]

68. Chiodini, N.; Vedda, A.; Fasoli, M.; Moretti, F.; Lauria, A.; Cantone, M.C.; Veronese, I.; Giampiero, T.; Brambilla, M.; Cannillo, B.; et al. Ce doped $\mathrm{SiO}_{2}$ optical fibers for remote radiation sensing and measurement. In Proceedings of the Fiber Optic Sensors and Applications VI, SPIE Defense, Security, and Sensing, Orlando, FL, USA, 27 April 2009.

69. Savard, N.; Potkins, D.; Beaudry, J.; Jirasek, A.; Hoehr, C.J.R.M. Characteristics of a Ce-Doped Silica Fiber Irradiated by 74 MeV Protons. Radiat. Meas. 2018, 114, 19-24. [CrossRef]

70. Cova, F.; Fasoli, M.; Moretti, F.; Chiodini, N.; Pauwels, K.; Auffray, E.; Lucchini, M.T.; Bourret, E.; Veronese, I.; d’Ippolito, E.; et al. Optical Properties and Radiation Hardness of Pr-Doped Sol-Gel Silica: Influence of Fiber Drawing Process. J. Lumin. 2017, 192, 661-667. [CrossRef]

71. Kononets, V.; Auffray, E.; Dujardin, C.; Gridin, S.; Moretti, F.; Patton, G.; Pauwels, K.; Sidletskiy, O.; Xu, X.; Lebbou, K. Growth of Long Undoped and Ce-Doped Luag Single Crystal Fibers for Dual Readout Calorimetry. J. Cryst. Growth 2016, 435, 31-36. [CrossRef]

72. Benaglia, A.; Lucchini, M.; Pauwels, K.; Tully, C.; Medvedeva, T.; Heering, A.; Dujardin, C.; Kononets, V.; Lebbou, K.; Aubry, N.; et al. Test Beam Results of a High Granularity Luag Fibre Calorimeter Prototype. J. Instrum. 2016, 11, P05004. [CrossRef]

73. Stancălie, A.; Esposito, F.; Ranjan, R.; Bleotu, P.; Campopiano, S.; Iadicicco, A.; Sporea, D. Arc-Induced Long Period Gratings in Standard and Speciality Optical Fibers Under Mixed Neutron-Gamma Irradiation. Sci. Rep. 2017, 7, 15845. [CrossRef]

74. Perry, M.; Niewczas, P.; Johnston, M. Effects of Neutron-Gamma Radiation on Fiber Bragg Grating Sensors: A Review. IEEE Sens. J. 2012, 12, 3248-3257. [CrossRef]

75. Krebber, K.; Henschel, H.; Weinand, U. Fibre Bragg Gratings as High Dose Radiation Sensors? Meas. Sci. Technol. 2006, 17, 1095. [CrossRef]

76. Gusarov, A.; Berghmans, F.; Deparis, O.; Fernandez, A.F.; Defosse, Y.; Mégret, P.; Decreton, M.; Blondel, M. High Total Dose Radiation Effects on Temperature Sensing Fiber Bragg Gratings. IEEE Photonics Technol. Lett. 1999, 11, 1159-1161. [CrossRef]

77. Zaghloul, M.A.; Wang, M.; Huang, S.; Hnatovsky, C.; Grobnic, D.; Mihailov, S.; Li, M.J.; Carpenter, D.; Hu, L.W.; Daw, J. Radiation Resistant Fiber Bragg Grating in Random Air-Line Fibers for Sensing Applications in Nuclear Reactor Cores. Opt. Express 2018, 26, 11775-11786. [CrossRef]

78. Sporea, D.; Stăncalie, A.; Neguţ, D.; Pilorget, G.; Delepine-Lesoille, S.; Lablonde, L. Comparative Study of Long Period and Fiber Bragg Gratings Under Gamma Irradiation. Sens. Actuators A Phys. 2015, 233, 295-301. [CrossRef] 
79. Stăncălie, A.; Sporea, D.; Neguţ, D.; Esposito, F.; Ranjan, R.; Campopiano, S.; Iadicicco, A. Long Period Gratings in Unconventional Fibers for Possible Use as Radiation Dosimeter in High-Dose Applications. Sens. Actuators A Phys. 2018, 271, 223-229. [CrossRef]

80. Berruti, G.M.; Vaiano, P.; Quero, G.; Pimentel Das Neves, T.F.; Boniello, A.; Consales, M.; Petagna, P.; Cusano, A. Analysis of Uncoated LPGs Written in B-Ge Doped Fiber Under Proton Irradiation for Sensing Applications At CERN. Sci. Rep. 2020, 10, 1344. [CrossRef] [PubMed]

81. Esposito, F.; Ranjan, R.; Stăncălie, A.; Sporea, D.; Neguț, D.; Becherescu, N.; Campopiano, S.; Iadicicco, A. Real-time Analysis of Arc-Induced Long Period Gratings under Gamma Irradiation. Sci. Rep. 2017, 7, 43389. [CrossRef] [PubMed]

82. Bradley, D.A.; Aziz, A.Z.; Knapton, A.J.; Abdul-Rashid, H.A.; Rahman, A.; Amin, Y.M.; Nor, R.M.; Maah, M.J.; Mahat, R. Optically Stimulated Luminescence in Beta Irradiated Ge-Doped Optical Fibre. In Proceedings of the IEEE 4th International Conference on Photonics (ICP), Melaka, Malaysia, 1 October 2013.

83. Kalnins, C.A.G.; Ebendorff-Heidepriem, H.; Spooner, N.A.; Monro, T.M. Radiation Dosimetry Using Optically Stimulated Luminescence in Fluoride Phosphate Optical Fibres. Opt. Mater. Express 2012, 2, 62-70. [CrossRef]

84. Kalnins, C.A.G.; Ebendorff-Heidepriem, H.; Spooner, N.A.; Monro, T.M. Optically Stimulated Luminescence in Fluoride Phosphate Glass Optical Fibres for Radiation Dosimetry. In Proceedings of the 3rd Asia Pacific Optical Sensors Conference (APOS), Sydney, Australia, 30 January 2012.

85. Whittaker, C.; Giroux, J.; Lariviere, D.; Allen, C.N.; Beaulieu, L. Colloidal Quantum Dot-Doped Optical Fibers for Scintillation Dosimetry. IEEE Trans. Nucl. Sci. 2020, 67, 1040-1044. [CrossRef]

86. Jang, K.W.; Yoo, W.J.; Moon, J.; Han, K.T.; Park, B.G.; Shin, D.; Park, S.Y.; Lee, B. Multi-Dimensional Fiber-Optic Radiation Sensor for Ocular Proton Therapy Dosimetry. Nucl. Instrum. Methods Phys. Res. Sect. A Accel. Spectrometers Detect. Assoc. Equip. 2012, 695, 322-325. [CrossRef]

87. Mones, E.; Veronese, I.; Vedda, A.; Loi, G.; Fasoli, M.; Moretti, F.; Chiodini, N.; Cannillo, B.; Brambilla, M. Ce-doped Optical Fibre as Radioluminescent Dosimeter in Radiotherapy. Radiation Measurements 2008, 43, 888-892. [CrossRef]

88. Pavan, P.; Zanella, G.; Zannoni, R.; Marigo, A. Spatial Resolution in X-ray Imaging with Scintillating Glass Optical Fiber Plates Nucl. Instrum. Methods Phys. Res. Sect. A Accel. Spectrometers Detect. Assoc. Equip. 1993, 327, 600-604. [CrossRef]

89. Hoehr, C.; Morana, A.; Duhamel, O.; Capoen, B.; Trinczek, M.; Paillet, P.; Duzenli, C.; Bouazaoui, M.; Bouwmans, G.; Cassez, A.; et al. Novel Gd ${ }^{3+}$-Doped Silica-Based Optical Fiber Material for Dosimetry in Proton Therapy. Sci. Rep. 2019, 9, 16376. [CrossRef]

90. Shi, Z.; Lv, S.; Tang, G.; Tang, J.; Jiang, L.; Qian, Q.; Zhou, S.; Yang, Z. Multiphase Transition toward Colorless Bismuth-Germanate Scintillating Glass and Fiber for Radiation Detection. ACS Appl. Mater. Interfaces 2020, 12, 17752-17759. [CrossRef] [PubMed]

91. Alshourbagy, M.; Bigotta, S.; Herbert, D.; del Guerra, A.; Toncelli, A.; Tonelli, M. Optical and Scintillation Properties of Ce ${ }^{3+}$ Doped Yalo 3 Crystal Fibers Grown By $\mu$-Pulling Down Technique. J. Cryst. Growth 2007, 303, 500-505. [CrossRef]

92. Zubair, H.T.; Rifiat, R.; Oresegun, A.; Hamidi, F.; Othman, J.; Khairina, M.D.; Basaif, A.; Ibrahim, S.A.; Abdul-Rashid, H.A.; Bradley, D.A. Fiber Optic Coupled Survey Meter for Norm and Low-Level Radioactivity Monitoring. Radiat. Phys. Chem. 2021, 188, 109682. [CrossRef]

93. Faustov, A.; Saffari, P.; Koutsides, C.; Gusarov, A.; Wuilpart, M.; Megret, P.; Zhang, L.; Kalli, K. Highly Sensitive Type IA Fiber Bragg Gratings as Sensors in Radiation Environments. In Proceedings of the 22nd International Conference on Optical Fiber Sensors (OFS), Beijing, China, 17 October 2012.

94. Esposito, F.; Stancalie, A.; Negut, C.D.; Campopiano, S.; Sporea, D.; Iadicicco, A. Comparative Investigation of Gamma Radiation Effects on Long Period Gratings and Optical Power in Different Optical Fibers. J. Lightwave Technol. 2019, 37, 4560-4566. [CrossRef]

95. Esposito, F.; Stancalie, A.; Negu, D.; Iadicicco, A.; Campopiano, S. Response of Long Period Gratings to Gamma and NeutronGamma Radiations. In Proceedings of the Seventh European Workshop on Optical Fibre Sensors, Limassol, Cyprus, 28 August 2019.

96. Rego, G.; Fernandez Fernandez, A.; Gusarov, A.; Brichard, B.; Berghmans, F.; Santos, J.; Salgado, H. Effect of Ionizing Radiation on The Properties of Long-Period Fiber Gratings. Appl. Opt. 2005, 44, 6258-6263. [CrossRef] [PubMed]

97. Kher, S.; Chaubey, S.; Kashyap, R.; Oak, S.M. Turnaround-Point Long-Period Fiber Gratings (TAP-LPGs) as High-Radiation-Dose Sensors. IEEE Photonics Technol. Lett. 2012, 24, 742-744. [CrossRef]

98. Sidletskiy, O.; Lebbou, K.; Kofanov, D. Micro-Pulling-Down Growth of Long Yag-And Luag-Based Garnet Fibres: Advances and Bottlenecks. CrystEngComm 2021, 23, 2633-2643. [CrossRef]

99. Farhi, H.; Belkahla, S.; Lebbou, K.; Dujardin, C. BGO Fibers Growth by $\mu$-Pulling Down Technique and Study of Light Propagation. Phys. Proc. 2009, 2, 819-825. [CrossRef]

100. Moore, M.E.; Trtik, P.; Lousteau, J.; Pugliese, D.; Brambilla, G.; Hayward, J.P. Neutron Imaging with Li-Glass Based Multicore SCIntillating FIber (SCIFI). J. Lightwave Technol. 2019, 37, 5699-5706. [CrossRef]

101. Cova, F.; Moretti, F.; Fasoli, M.; Chiodini, N.; Pauwels, K.; Auffray, E.; Lucchini, M.T.; Baccaro, S.; Cemmi, A.; Bártová, H.; et al. Radiation Hardness of Ce-Doped Sol-Gel Silica Fibers for High Energy Physics Applications. Opt. Lett. 2018, 43, 903-906. [CrossRef]

102. Lv, S.; Tang, J.; Chen, J.; Liu, P.; Guo, J.; Ma, Y.; Qiu, J.; Zhou, S. Full-Inorganic Micro-Fiber Probe for Real-Time Radiation Monitoring. Adv. Mater. Technol. 2021, 6, 2000696. [CrossRef]

103. Aktas, O.; Ozgur, E.; Tobail, O.; Kanik, M.; Huseyinoglu, E.; Bayindir, M. A New Route for Fabricating On-Chip Chalcogenide Microcavity Resonator Arrays. Adv. Opt. Mater. 2014, 2, 618-625. [CrossRef] 
104. Gumennik, A.; Wei, L.; Lestoquoy, G.; Stolyarov, A.M.; Jia, X.; Rekemeyer, P.H.; Smith, M.J.; Liang, X.; Grena, B.J.; Johnson, S.G.; et al. Silicon-in-Silica Spheres via Axial Thermal Gradient in-Fibre Capillary Instabilities. Nat. Commun. 2013, 4, 2216. [CrossRef] [PubMed]

105. Xu, B.; Ma, S.; Xiang, Y.; Zhang, J.; Zhu, M.; Wei, L.; Tao, G.; Deng, D. In-Fiber Structured Particles and Filament Arrays from the Perspective of Fluid Instabilities. Adv. Fiber Mater. 2020, 2, 1-12. [CrossRef]

106. Wei, L.; Hou, C.; Levy, E.; Lestoquoy, G.; Gumennik, A.; Abouraddy, A.F.; Joannopoulos, J.D.; Fink, Y. Optoelectronic Fibers via Selective Amplification of In-Fiber Capillary Instabilities. Adv. Mater. 2017, 29, 1603033. [CrossRef]

107. Song, S.; Lønsethagen, K.; Laurell, F.; Hawkins, T.; Ballato, J.; Fokine, M.; Gibson, U.J. Laser Restructuring and Photoluminescence of Glass-Clad GaSb/Si-Core Optical Fibres. Nat. Commun. 2019, 10, 1790. [CrossRef]

108. Peacock, A.C.; Healy, N.; Suhailin, F.; Mailis, S.; Ballato, J.; Gibson, U. Crystalline Core Silicon Fibers for Optoelectronic Applications. In Proceedings of the Integrated Photonics Research. Silicon and Nanophotonics, Vancouver, BC, Canada, 18-20 July 2016.

109. Peacock, A.C.; Healy, N. Semiconductor Optical Fibres for Infrared Applications: A Review. Semicond. Sci. Technol. 2016, 31, 103004. [CrossRef]

110. Wu, W.; Balci, M.H.; Song, S.; Liu, C.; Fokine, M.; Laurell, F.; Hawkins, T.; Ballato, J.; Gibson, U.J. CO 2 Laser Annealed SiGe Core Optical Fibers with Radial Ge Concentration Gradients. Opt. Mater. Express 2020, 10, 926-936. [CrossRef]

111. Wu, W.; Balci, M.H.; Mühlberger, K.; Fokine, M.; Laurell, F.; Hawkins, T.; Ballato, J.; Gibson, U.J. Ge-capped SiGe Core Optical Fibers. Opt. Mater. Express 2019, 9, 4301-4306. [CrossRef]

112. Luo, Q.; Tang, G.; Sun, M.; Qian, G.; Shi, Z.; Qian, Q.; Yang, Z. Single Crystal Tellurium Semiconductor Core Optical Fibers. Opt. Mater. Express 2020, 10, 1072-1082. [CrossRef]

113. Zhao, Z.; Mao, Y.; Ren, L.; Zhang, J.; Chen, N.; Wang, T. $\mathrm{CO}_{2}$ Laser Annealing of Ge Core Optical Fibers with Different Laser Power. Opt. Mater. Express 2019, 9, 1333-1347. [CrossRef]

114. Noor, N.M.; Jusoh, M.A.; Razis, A.; Alawiah, A.; Bradley, D.A. Flat Ge-doped Optical Fibres for Food Irradiation Dosimetry. AIP Conf. Proc. 2015, 1657, 100007.

115. Tajuddin, H.A.; Wan, M.; Sani, S.; Hashim, S.A. Development of Optical Fibers for Food Irradiation Dosimeter. Malays. J. Fundam. Appl. Sci. 2019, 15, 109-111. [CrossRef]

116. Fernandez, A.F.; Brichard, B.; O’Keeffe, S.; Fitzpatrick, C.; Lewis, E.; Vaille, J.R.; Dusseau, L.; Jackson, D.A.; Ravotti, F.; Glaser M.; et al. Real-Time Fibre Optic Radiation Dosimeters for Nuclear Environment Monitoring Around Thermonuclear Reactors. Fusion Eng. Des. 2008, 83, 50-59. [CrossRef]

117. Fernandez, A.F.; Jackson, D.A. Real-Time Fibre Optic Radiation Dosimeters for Nuclear Surgical Medicine and Nuclear Environment Monitoring. In Proceedings of the Optical Fiber Sensors, OSA Technical Digest (CD), Cancun, Mexico, 32-27 October 2006.

118. Faustov, A.V.; Gusarov, A.; Wuilpart, M.; Fotiadi, A.; Liokumivich, L.B.; Zolotovskiy, I.O.; Tomashuk, A.L.; Schoutheete, T.D.; Mégret, P. Remote Distributed Optical Fibre Dose Measuring of High Gamma-Irradiation with Highly Sensitive Al-and P-Doped Fibres. In Proceedings of the SPIE Optics + Optoelectronics, Prague, Czech Republic, 3 May 2013.

119. Sylvie, D.L.; Sylvain, G.; Marcel, L.; Johan, B.; Is Ab Elle, P.; Aziz, B.; Emmanuel, M.; Georges, H.; Stéphanie, L.; Jean-Louis, A.J.S France's State of the Art Distributed Optical Fibre Sensors Qualified for the Monitoring of the French Underground Repository for High Level and Intermediate Level Long Lived Radioactive Wastes. Sensors 2017, 17, 1377.

120. Remy, L.; Cheymol, G.; Gusarov, A.; Morana, A.; Marin, E.; Girard, S. Compaction in Optical Fibres and Fibre Bragg Gratings Under Nuclear Reactor High Neutron and Gamma Fluence. IEEE Trans. Nucl. Sci. 2016, 63, 2317-2322. [CrossRef]

121. Rozaila, Z.S.; Khandaker, M.U.; Abdul Sani, S.F.; Sabtu, S.N.; Amin, Y.M.; Maah, M.J.; Bradley, D.A. Environmental Monitoring Through Use of Silica-based TLD. J. Radiol. Prot. 2017, 37, 761-779. [CrossRef]

122. Francesca, D.; Vecchi, G.L.; Girard, S.; Alessi, A.; Brugger, M. Radiation Induced Attenuation in Single-Mode Phosphosilicate Optical Fibers for Dosimetry. IEEE Trans. Nucl. Sci. 2018, 65, 126-131. [CrossRef]

123. Fernandez, A.F.; Brichard, B.; Alasia, D.; Abrardi, L.; Thévenaz, L. The Effects of Gamma-Radiation on the Properties of Brillouin Scattering in Standard Ge-doped Optical Fibres. Meas. Sci. Technol. 2006, 17, 180-183.

124. Benton, E.R.; Benton, E.V. Space Radiation Dosimetry inLow-Earth Orbit and Beyond. Nucl. Instrum. Methods Phys. Res. Sect. B Beam Interact. Mater. At. 2001, 184, 255-294. [CrossRef]

125. Suter, J.J.; Poret, J.C.; Rosen, M.J. Fiber Optic Ionizing Radiation Detector. IEEE Trans. Nucl. Sci. 1992, 39, 674-679. [CrossRef]

126. Boeder, C.; Adams, L.; Nickson, R. Scintillating Fibre Detector System for Spacecraft Component Dosimetry. In Proceedings of the Second European Conference on Radiation and its Effects on Components and Systems, Saint Malo, France, 13-16 September 1993.

127. Veronese, I.; Cantone, M.C.; Chiodini, N.; Coray, A.; Fasoli, M.; Lomax, A.; Mones, E.; Moretti, F.; Vedda, A. Feasibility Study for the Use of Cerium-Doped Silica Fibres in Proton Therapy. Radiat. Meas. 2010, 45, 635-639. [CrossRef]

128. Vedda, A.; Chiodini, N.; di Martino, D.; Fasoli, M.; Keffer, S.; Lauria, A.; Martini, M.; Moretti, F.; Spinolo, G.; Nikl, M.; et al. $\mathrm{Ce}^{3+}$-doped Fibers for Remote Radiation Dosimetry. Appl. Phys. Lett. 2004, 85, 6356-6358. [CrossRef]

129. Mones, E.; Veronese, I.; Moretti, F.; Fasoli, M.; Loi, G.; Negri, E.; Brambilla, M.; Chiodini, N.; Brambilla, G.; Vedda, A. Feasibility Study for the Use of $\mathrm{Ce}^{3+}$-Doped Optical Fibres in Radiotherapy. Nucl. Instrum. Methods Phys. Res. Sect. A Accel. Spectrometers Detect. Assoc. Equip. 2006, 562, 449-455. [CrossRef] 
130. Ong, C.L.; Kandaiya, S.; Kho, H.T.; Chong, M.T. Segments of a Commercial Ge-doped Optical Fiber as a Thermoluminescent Dosimeter in Radiotherapy. Radiat. Meas. 2009, 44, 158-162. [CrossRef]

131. Begum, M.; Rahman, A.; Zubair, H.T.; Abdul-Rashid, H.A.; Yusoff, Z.; Begum, M.; Alkhorayef, M.; Alzimami, K.; Bradley, D.A. The Effect of Different Dopant Concentration of Tailor-Made Silica Fibers in Radiotherapy Dosimetry. Radiat. Phys. Chem. 2017, 141, 73-77. [CrossRef]

132. Noor, N.M.; Hussein, M.; Bradley, D.A.; Nisbet, A. Investigation of The Use of Ge-doped Optical Fibre for in Vitro IMRT Prostate Dosimetry. Nucl. Instrum. Methods Phys. Res. Sect. A Accel. Spectrometers Detect. Assoc. Equip. 2011, 652, 819-823. [CrossRef]

133. Hashim, S.; Al-Ahbabi, S.; Bradley, D.A.; Webb, M.; Jeynes, C.; Ramli, A.T.; Wagiran, H. The Thermoluminescence Response of Doped $\mathrm{SiO}_{2}$ Optical Fibres Subjected to Photon and Electron Irradiations. Appl. Radiat. Isot. 2009, 67, 423-427. [CrossRef]

134. Hashim, S.; Bradley, D.A.; Saripan, M.I.; Ramli, A.T.; Wagiran, H. The Thermoluminescence Response of Doped SiO $2 \mathrm{Optical}$ Fibres Subjected to Fast Neutrons. Appl. Radiat. Isot. 2010, 68, 700-703. [CrossRef]

135. Lambert, J.; McKenzie, D.R.; Law, S.; Elsey, J.; Suchowerska, N. A Plastic Scintillation Dosimeter for High Dose Rate Brachytherapy. Phys. Med. Biol. 2006, 51, 5505-5516. [CrossRef]

136. Issa, F.; Hugtenburg, R.P.; Nisbet, A.; Bradley, D.A. Novel High Resolution I-125 Brachytherapy Source Dosimetry Using Ge-Doped Optical Fibres. Radiat. Phys. Chem. 2013, 92, 48-53. [CrossRef]

137. Palmer, A.L.; di Pietro, P.; Alobaidli, S.; Issa, F.; Doran, S.; Bradley, D.; Nisbet, A. Comparison of Methods for the Measurement of Radiation Dose Distributions in High Dose Rate (HDR) Brachytherapy: Ge-Doped Optical Fiber, EBT3 Gafchromic Film, and Presager (R) Radiochromic Plastic. Med Phys. 2013, 40, 061707. [CrossRef] [PubMed]

138. Espinosa, G.; Bogard, J.S. Optically Stimulated Luminescence Response of Commercial $\mathrm{SiO}_{2}$ Optical Fiber. J. Radioanal. Nucl. Chem. 2008, 277, 125-129. [CrossRef]

139. Mahdiraji, G.A.; Dermosesian, E.; Safari, M.J.; Adikan, F.R.M.; Bradley, D.A. Collapsed-Hole Ge-Doped Photonic Crystal Fiber as a Diagnostic Radiation Dosimeter. J. Lightwave Technol. 2015, 33, 3439-3445. [CrossRef]

140. Alyahyawi, A.; Jupp, T.; Alkhorayef, M.; Bradley, D.A. Tailor-made Ge-doped Silica-Glass for Clinical Diagnostic X-Ray Dosimetry. Appl. Radiat. Isot. 2018, 138, 45-49. [CrossRef]

141. Caretto, N.; Chiodini, N.; Moretti, F.; Origgi, D.; Tosi, G.; Vedda, A. Feasibility of Dose Assessment in Radiological Diagnostic Equipments Using Ce-Doped Radio-Luminescent Optical Fibers. Nucl. Instrum. Methods Phys. Res. Sect. A Accel. Spectrometers Detect. Assoc. Equip. 2010, 612, 407-411. [CrossRef]

142. Helou, N.A.; Hamzaoui, H.E.; Capoen, B.; Bouwmans, G.; Cassez, A.; Ouerdane, Y.; Boukenter, A.; Girard, S.; Chadeyron, G.; Mahiou, R.; et al. Radioluminescence and Optically Stimulated Luminescence Responses of a Cerium-Doped Sol-Gel Silica Glass Under X-Ray Beam Irradiation. IEEE Trans. Nucl. Sci. 2018, 65, 1591-1597. [CrossRef]

143. Fernandez, A.F.; Rodeghiero, P.; Brichard, B.; Berghmans, F.; Hartog, A.H.; Hughes, P.; Williams, K.; Leach, A.P. Radiation-tolerant Raman Distributed Temperature Monitoring System for Large Nuclear Infrastructures. IEEE Trans. Nucl. Sci. 2005, 52, 2689-2694. [CrossRef]

144. Huston, A.; Justus, B.; Falkenstein, P.; Miller, R.; Ning, H.; Altemus, R. Remote Optical Fiber Dosimetry. Nucl. Instrum. Methods Phys. Res. Sect. B Beam Interact. Mater. At. 2001, 184, 55-67. [CrossRef]

145. Evans, B.D.; Sigel, G.H.; Langworthy, J.B.; Faraday, B.J. The Fiber Optic Dosimeter on the Navigational Technology Satellite 2. IEEE Trans. Nucl. Sci. 1978, 25, 1619-1624. [CrossRef]

146. Moss, C.E.; Casperson, D.E.; Echave, M.A.; Edwards, B.C.; Miller, J.R.; Saylor, W.W.; Sweet, M.R.; Valencia, J.E. A Space Fiber-Optic X-ray Burst Detector. IEEE Trans. Nucl. Sci. 1994, 41, 1328-1332. [CrossRef]

147. Terasawa, K.; Doke, T.; Hasebe, N.; Kikuchi, J.; Kudo, K.; Murakami, T.; Takeda, N.; Tamura, T.; Torii, S.; Yamashita, M. Scintillating Fiber Camera for Neutron Dosimetry in Spacecraft. Nucl. Instrum. Methods Phys. Res. Sect. A Accel. Spectrometers Detect. Assoc. Equip. 2001, 457, 499-508. [CrossRef]

148. iXblue. iXblue on Board the International Space Station with the LUMINA Dosimeter. Available online: https://photonics.ixblue. com/news (accessed on 29 April 2021).

149. Barrias, A.; Casas, J.R.; Villalba, S. A Review of Distributed Optical Fiber Sensors for Civil Engineering Applications. Sensors 2016, 16, 748. [CrossRef] [PubMed]

150. Yilmaz, G.; Karlik, S.E. A Distributed Optical Fiber Sensor for Temperature Detection in Power Cables. Sens. Actuators A Phys. 2006, 125, 148-155. [CrossRef]

151. London, Y.; Sharma, K.; Diamandi, H.H.; Hen, M.; Bashan, G.; Zehavi, E.; Zilberman, S.; Berkovic, G.; Zentner, A.; Mayoni, M.; et al. Opto-Mechanical Fiber Sensing of Gamma Radiation. J. Lightwave Technol. 2021, 39, 6637-6645. [CrossRef] 